\title{
Erwägungen zu neuen Stelen König Nabonids
}

\section{Von W. Röllig-Münster}

Am Ende der Geschichte Babyloniens als eines selbständigen Staates steht ein Herrscher, dessen Persönlichkeit eigenartig zwielichtig erscheint. Eine merkwürdige Mischung von historischer Wahrheit und Legende bestimmt die Überlieferung, die von ihm geblieben ist, und dadurch wird sogar das gewaltige geschichtliche Geschehen überdeckt, das sich in seinen Tagen abspielt, der Fall des babylonischen Reiches. Das ist erklärlich, denn es gab keinen „Zusammenbruch“. Die Herrschaft ging auf den Achaimeniden über, aber fast ohne Gewaltanwendung. Die Herrscher wurden zu Beherrschten, doch das Herrschaftssystem blieb im Grunde gleich. Der letzte König Babyloniens hingegen trug das seine dazu bei, daß sich bald die Legende seiner Gestalt bemächtigte. Ungewöhnlich wie die Wege, die er auf politischem und religiösem Gebiet beschritt, sind auch die Inschriften, die er uns hinterließ. Wir sind auch heute noch weit davon entfernt, uns ein klares Bild von den Vorgängen machen zu können, die sich während der I7 Jahre seiner Regierung abspielten.

Wichtige Funde der letzten Jahre tragen zur Klärung einiger Fragen entscheidend bei; sie werfen allerdings auch Probleme auf, die noch der Lösung bedürfen. In Harrān kamen völlig unerwartet drei Stelen ans Licht, die in die alte Moschee des Ortes eingebaut waren, ursprünglich aber im Tempel des Mondgottes aufgestellt gewesen sein dürften. Eine davon ist Duplikat zu der bereits seit 1906 bekannten Stele der Mutter Nabonids, die zuletzt von B. Landsberger behandelt wurde ${ }^{1}$. Dieser Text wird nun an verschiedenen Stellen ergänzt und liegt damit fast vollständig vor ${ }^{2}$. Die beiden anderen Stelen $\left(\mathrm{H}_{2} \mathrm{~A} / \mathrm{B}\right)$

${ }^{1}$ B. Landsberger, Die Basaltstele Nabonids von Eski-Harran. Halil Edhem hâtǐra kitabì Vol. I. Türk Tarih Kurumu Yayı̆nlarĭndan VII. Seri No. 5 (Ankara 1947) II5-I5I. 3 Tafeln. Im folgenden: H. Edhem Memorial.

${ }^{2} \mathrm{H}_{1} \mathrm{~B}$ der Bearbeitung von C. J. Gadd, The Harran Inscriptions of Nabonidus. Anatolian Studies Vol. 8 (I958) 35-92. Pl. I-XVI. Im Folgenden zitiert als Gadd mit den dort gebrauchten Siglen: $\mathrm{H}_{1} \mathrm{~A} / \mathrm{B}$ für die Stelen der Mutter Nabonids; $\mathrm{H}_{2} \mathrm{~A} / \mathrm{B}$ für die Stelen des Königs. Die Edition Gadds, die im wesentlichen auf den auch in Photographie beigegebenen Latex-Abklatschen 
weisen ebenfalls einander duplizierende Inschriften auf, die vom König selbst stammen und im Stile einer Bauinschrift für den Tempel Ehulhul einen politischen Rechenschaftsbericht enthalten, dem sachlich nur die Stele von Hille ${ }^{3}$ zur Seite zu stellen ist.

\section{Die Stelen $\mathrm{H}_{2} \mathrm{~A} / \mathrm{B}^{4}$}

I I $i$-piš-ti a $\operatorname{Sinn}^{5}$ rabīti(GAL) ${ }^{t i}$ šá $\langle i n a\rangle i l a \bar{n} i^{\text {meśs }} \dot{u}$ d $i s ̌-t a r / i s ̌ t a r(\mathrm{XV})$

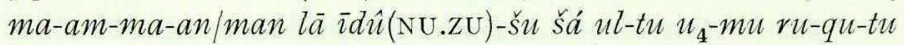
a-na mäti|ma-a-tu la tu-ri-du ${ }^{6}$ niš $\bar{e}^{\text {meš }}$ mãti $\langle l a\rangle i p-p a l-s u-m a$ i-na tup-pi la iš-ț-ru-ma la iš-tak-ka-nu

5 a-na $u_{4}-m u$ sa-a-ti ${ }^{\text {a Sin bèl } i l a ̄ n i}{ }^{\text {meš }} u$ díštar(INANNA)/ištar $a$-šíbu-tui

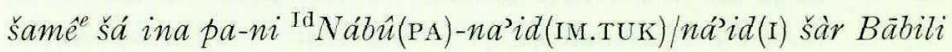
(TIN.TIR) $)^{\mathbf{k j}}$

$u l-t u$ šamêe tal-li-ku a-na-ku ${ }^{\text {Id }} N a ́ b \hat{u}-n a ́ i d$

$[m \bar{a}] r u^{!} e-d u^{7}$ šá man-ma-an la $i$-šu-ús šá šarru-u-tú ina lib-bi-ja la tab-šu-ú ilāni ${ }^{\text {meš }} u$ dišstar a-na muhhi$[j] a ?$ ú-șal-lu-ú ì aSin a-na šarru-ú-tiltú?

[i]b-ba-an-ni ina šá-at mu-ši šutta(MAš.GE $\left.{ }_{6}\right)$ î-šab-ra-an-[ni]

beruht, soll noch nicht als abschließend betrachtet werden, doch ist es außerordentlich zu begrüßen, daß die Texte so rasch veröffentlicht wurden. Kollationen am Stein werden zweifellos noch einige schwierige Stellen klären können, einige Verbesserungen ließen sich auch an Hand der Photographien anbringen. Vgl. dazu den Aufsatz von W. L. Moran, Notes on the New Nabonidus Inscriptions, OrNS 28 (I959) I30-I40. W. von Soden danke ich herzlich für eine Durchsicht des Manuskripts, wichtige Hinweise und kritische Bemerkungen.

${ }^{3} \mathrm{VAB}_{4}, 270-289$ (Nabonid Nr. 8). Die Edition von V. Scheil, RT I8 (I896) I $5-29$ enthält auch 3 recht klare Photographien des Steines und eines $\mathrm{Ab}$ klatsches.

4 Transkription und Übersetzung der Nabonid-Stelen im Anschluß an Gadd und die dort publizierten Photos. Haupttext ist die Stele A, deren Kolumneneinteilung wie bei Gadd zugrunde gelegt wird. Die orthographischen Varianten von $B$ wurden in den Text eingefügt, wobei jeweils die nach dem Schrägstrich gebuchte Schreibung dieser Stele entspricht.

${ }^{5}$ Immer ${ }^{\mathrm{d}} \mathrm{xxx}$.

${ }^{6} \mathrm{~B}$ hat nach diesem Wort noch Spuren von 2 ? Zeichen. Gadds Lesung $-u($ ?)-ni(?) läßt sich kaum verifizieren, ša ist ebenfalls ausgeschlossen, da die Texte ausschließlich das Zeichen $\breve{s} a ́(\mathrm{NÍG}$ ) verwenden. W. von Soden schlägt vor: zABni.

7 Vorschlag R. Borgers, vgl. $\mathrm{H}_{1} \mathrm{~B} \mathrm{I} 40$; II I3.

${ }^{8}$ In $\mathrm{B}$ sind zwei Zeilen zerstört. 


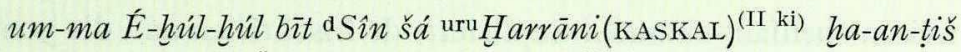
$e-p u$-uš mātāte ${ }^{\text {meš }} k a-l a-s ̌ i-n a ~ a-n a ~ q a \bar{t} e^{-I I}-k a$ lu-mál-la niše ${ }^{\text {meš }}$ mārēemeš Bäbili(TIN.TIR) ${ }^{\mathrm{ki}} B a ̈ r-s i p^{\mathrm{ki}}$

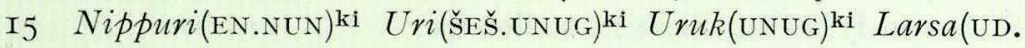
$\mathrm{UNUG})^{\mathrm{ki}}$ lúšangể(SANGA) ${ }^{\mathrm{me}}$

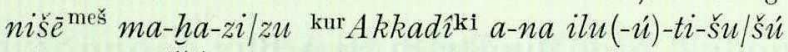

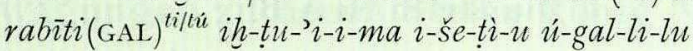

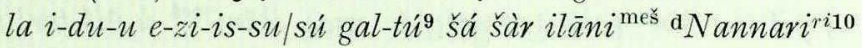
par-și-šú-nu im-šu-'i-i-ma $i$-dib-bu-bu sur-ra-a-tú

20 u la ki-na-a-tú ki-ma kalbi (UR.GIR ${ }_{\mathrm{x}}$ ) it/i-ta-nak-ka-lu/kal a-ha-meš di-’u u su-gù/gu-ú ina lib-bi-šú-nu ú-šab-šu-ú ú-sa(-ah)-h̆i-ir/ri nišse $\bar{e}^{-\mathrm{ses}}$ māti u ana/a-na-ku ul-tu āli-ja Bäbili(TIN.TIR) ${ }^{\mathbf{k i}}$ ú-še-ri-qa-an-ni-ma u-ru-uh uru $T e-m a-a / a^{3}$ uru $D a-d a-\langle n u\rangle^{11}$ uru $P a-d a k-k u^{12}$

25 uru $H i-i b / b i-r a-a$ uru $J a ́-d i-h n u ~ u$ a-di uru JálJa-at-ri-bu Io šanāte (MU.AN.NA) ${ }^{\text {meš }}$ at-tal-[l]a-ku/lak qí-rib-š́u-un a-na ăli-ja/já Bäbili(TIN.TIR) ki la e-ru-ub ina a-mat dîn

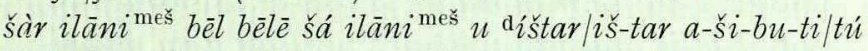
šá šamêe $u$-šal-lim/li-mu-ủ ina qi-bit d Sîn dNannari ${ }^{r i}$

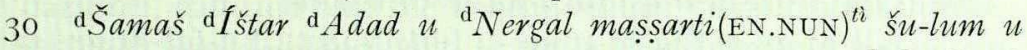
balāti(TIN)

ip-qí-du it-ti-jaljá ina šatti(MU) šá-a-š $u^{13}$ ina ${ }^{14}$ itu Nisanni

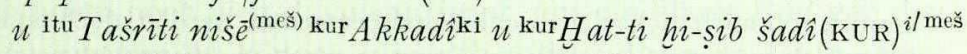
u tam-ti i-leq-qu-nim-ma ina dan-na-túlti um-ma-a-tú ituSimāni itu $D u^{2} \bar{u} z i$ itu $A b i$ itu Ulüli itu Tašr

35 ina kal ${ }^{15}$ šanäte(MU.AN.NA) ${ }^{\text {meš }}$ an-na-a-ti/tú

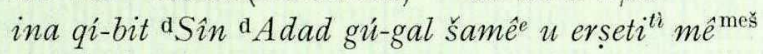

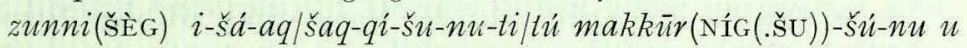
$b u-s ̌ a ́ a-s ̌ u ́-m u$ ina šu-lum ${ }^{15}$ ir-ru-bu-nu a-na mah-ri/IGI-jálja ina a-mat a Sin $u$ d f́star/Iš-tar be-let MÈ/ta-ḩa-zu šá mu-kúr-ti|tú u su-lum$m u-\dot{u} / u$

9 Das Wort ist in A ausgelassen. S. dazu (auch mit $u z z u$, Zorn") AHw. 275 b; CAD G 20 b.

10 Schreibung stets dŠEš.KI ${ }^{r i}$, offenbar promiscue mit dSin gebraucht, nicht nur ",Gott des Neumondes".

11 Nach B: uruDa-da-nu.

$12 \mathrm{~B}$ vertauscht diesen und den folgenden Namen miteinander.

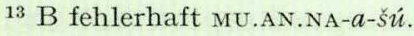

$14 \mathrm{~B}$ : om.

15 Nach B. 
40 ina ba-li-šu/šú ina mā[ti] la $i b-b a-a ́ s ̌-s ̌ u-u^{16}$ i $k a k-k u$ la in-né-ep-pu-šu/šú qát-su anàla-na muh-ȟi-ší-nu ta-ap-ri-ik-ma $a^{17}$ šàr? $m a \bar{t}$ ? Mi-șir uru $M a-d a-a-a$ māt A-ra-bi ${ }^{18} u$ nap-ḩar šarrāni meśs na-ki-ru-tú a-na su-lum-mu-ú u tu-ub-ba-a-ti i-šap-pa-ru-ma

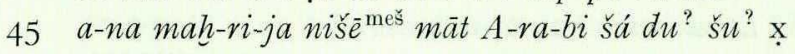
$i s^{2}-q a l$ $u e \times \times[$

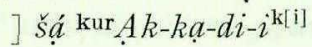
ha-ba-ti u la-qé?-e? šá bu-še-e iz-zi-zu

II $\quad i$-na a-mat 'Sin dNergal kak-ki-šs-nu

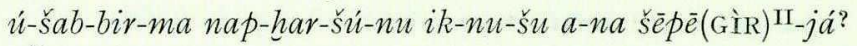

dŠ̆amaš bèl ur-ti šá ina ba-li-šú pu-ú la ip-pat-tu-ú u pu-u la uk-ta-at-ta-mu

5 mu-šal-lim qi-bit a Nannariri abi(AD) ba-ni-šu? niš $e^{-m e s ̌ s} \operatorname{kur} A k k a d \hat{k i} u$ kurHat-ti šá ú-mál-lu-u qātü ${ }^{\mathrm{I}}-\dot{u}-a$ pu-i u lib-bi ke(-i)-nù it-t $\left[i^{?}-j\right] a$ ? $i \breve{s}-k u n-s ̌ u-n u-t i-m a$ i-na-aș-sa-ru massarti(EN.NUN) ${ }^{t i}$ í-šal-la-mu qi-bi-ti/bit ina $\mid i{ }^{?}-n a$ ? pi-rik šadi ${ }^{i}$ meš

Io né-su-ti ur-h̆u pa-rik-túlti šá at-tal-la-ku ro šanāte(MU.AN.NA) meš ik-šu-dam(-ma) a-dan-nu

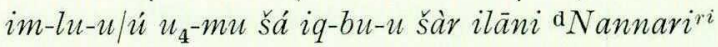
ina itu Tašrnti UD I7 KÁM $u_{4}$-mu dSin im/i-ma-ag-gàr pi-šir-šú dSin bèlu šá ilāni meš19 šá ina UD I KÁM

I5 KU dA-nim zi-kir-šu šamêe ta-lap-pa-tú $u$ erseti ${ }^{\text {ti }}$ ta-he-ep-pu-ú/u ha-mi-im paraș(PA.AN) d A-nì-ú-tú ${ }^{20}$ mu-gam-mi-ir PA.AN/pa-ra-as d En-líl-ú-tú

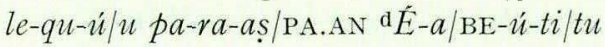
šá nap-h̆ar gi-mi-ir pa-ra-aș/PA.AN šamê ina qätẽ $e^{-I I} / q a-t i-s ̌ u ́$

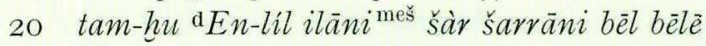
šá a-na qi-bi-ti-šu/šú la $i$-tur-ru is a-mat-su la ta-qab-bu-ú/u šinī(II)-šri šá pu-luh-ti ilu-ti-šú rabiti šamêe

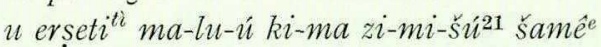
$25 u$ erșeti ${ }^{t i}$ sah-pu šá la ka-a-šú man-nu

16 GÁL- $u$.

17 Das Folgende teilweise nach B ergänzt.

18 B Kol. II I. Dort ab Z. 4 (= A 45/46) nur noch undeutliche Spuren.

$19 \mathrm{~B}$ : EN DINGIR.

20 B: dA-nù-tí. Das letzte Zeichen steht bereits auf der nächsten Zeile (vgl. A I $9 /$ IO).

21 Nach B. Das Folgende öfter nach B ergänzt. 
mi-na-a ip-pu-uš mätu šá lìb-bi-ka a-šab-šu ub-lu pu-iuh-tú ilu-ti-ka rabitit ina lib-bi-šú ta-šak-kan-ma a-na $u_{4}$-mu ru-qu-ti|tú $i s ̌ d e$ (suHưš) ${ }^{\text {meš }}$-šú $i-k u-u n-n u / n a$ mātu šá lib-ba-ka

$30 \quad h a-\dot{p} u-s ̌ r u ~ u b-l u \mid l a$ pu-luh-ta-ka ul-tu lib-bi-šú ta-ni-is-si-e-mu ta-na-an-di-iš?

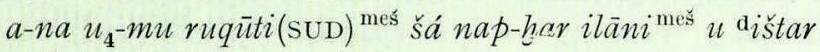

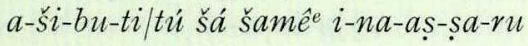
si-it pi-i-šú ú-šal-la-mu qi-bi-ti|bit

$35{ }^{\mathrm{d} N a n n a r i}{ }^{r i}$ abi(AD) ba-ni-šú-un mu-gam-mi-ir/mir paraș(PA.AN) šamêe u erșetit šáa a-bal qí-bi-ti-šú sir-tú šá $u_{4}-m i$-šam-ma ina šá-ma-mi/mu i-qab-bu-u mātu la ta-an/tan-na-(an-)du-u u nu-uir ina KUR/ma-a-tú la ib-ba-(áš-) šu-u/ $/ u^{22}$

$40 i_{\bar{a}} i^{\text {meš }} k \bar{\imath} m a$ [qa]nê(GI) $i$-šub-bu i-na-ar-ru-ṭ̂ dA-nun-na-ki šá la-pa-ni qi-bit ilu-ti-šú

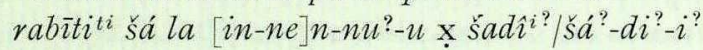

$\mathrm{x} \times \mathrm{x}[$

$\mathrm{x} \times \mathrm{x} \times \mathrm{x} \times \mathrm{x}$

45

$\mathrm{x}$
$\mathrm{x}$
$\mathrm{x}$

$\mathrm{x}[$

$\mathrm{x} x$

$\mathrm{x} \times$
] x x ma-am-ma-an?

] ŠID [ ] $\quad \check{a} a ́ ? ? a p ? ? l a ? ? a$

] $\mathrm{x} \times$ [ ] $\quad$ ri iš mu

]-a-nu ilāni $i^{\mathrm{mes}}$

] $l i ? ? a ?$ ?

$50 \times[$

III<smiles></smiles>

$\mathrm{x} \times \mathrm{x} \times k a^{? ?} t i$

] $\mathrm{x} \times \mathrm{x} \times \mathrm{x} \times \mathrm{x} \times$

[1ú] šä'ili(EN.ME.LI) a-lak-tú ul par-sat a[t-ti]l-[ma]

[ina š] at mu-ši šuttu(MÁš.GE $)$ pár-da-at a-di a-mat [ ] im-li šattu(MU) ik-šu-du a-dan-nu šá [

5 ul-tu uru Te-ma-a $\dot{u}$-[

Bäbili(TIN.TIR) ${ }^{\mathbf{k i}} \bar{a} l$ be-lu-t[i-ja ] x [ ] $i$-mu-ru-max x x [ ] $[$ [ ] šul?-ma kád? $-r a-a$ il?-qu-ú a-na [ ] $]^{23}$ - ] x x x šaryāmi meš qer-bu-tú

Io il-lu-nim-ma u-na-áššśá-qu šeppe $\bar{e}^{\mathrm{II}-j a ́}$ u ru-qu-tú iš-mu-u ip-la-hnu ilu-ut-su rabitu ${ }^{t u ́}$ ilāni $^{\text {meš }} u$ dístarāte ${ }^{(\text {meš }) ~ s ́ a ́ ~ i p-p a r-d u-m a ~} i$-ri-qa

${ }^{22}$ Ende von B Kol. II. Einige Ergänzungen von A II 4 off. nach B III Iff. Allerdings ist auch dieser Text stark beschädigt.

${ }_{23}$ Nach B. Im folgenden Ergänzungen der beschädigten Kolumne III von Text A häufig nach $B$. 
is-sah-ru-nim-ma i-qab-bu-ú/u ba-ni-ti

u ina par-su lúbārî̀ (HAL) iš-šá-kin ševr(UZU) dum-qi-já ina nu-uh-šú

I5 $u$ tuhh-du u hée-gál-la niš $e^{\text {meśs }}-j a ́$ ina šadî $i^{\text {meš }}$ ni-su-tiltú

arláš-te-ed-dam-ma ina šá-lim-ti aṣ-bat $\dot{u} / u^{?}$-ru-uh

ma-ti/KUR-ja a-mat ilu-ti-šri rabititi at-ta-șa-ar-ma/mu

la e-gi la a-šit a-ḩi la ad-du u-šad-kam-ma

niš $e^{-\operatorname{meš}}$ kur Akkadîki $u$ kurHat-ti ul-tu pa-at kurMi-sir

20 tam-ti e-lit a-di tam-ti šap-lit šá dSin šàr ilāni(DINGIR(.DINGIR))

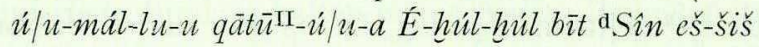

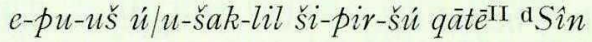

dNin-gal dNusku u dSa-dàr-nun-na ul-tu

Šu-an-na àl šarru(-u)-ti-ja|já a-șa-bat-ma ina hri-da-a-tú

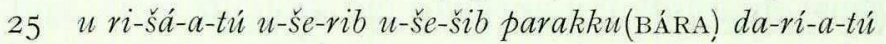

ni-qu-u taš- $[r i] /\langle r i\rangle-i h$-tú ma-har-šri-nu aq-qí-ma

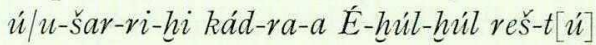

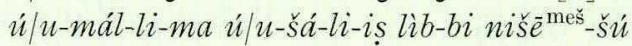

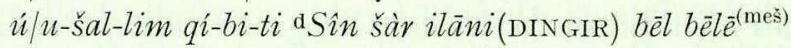

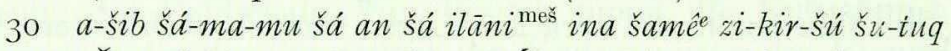

dŠamaš šá ni-bu-šú dNusku dÍstar dAdad " dNergal

šá ú/u-šal-lim-ù qi-bit dNannariri

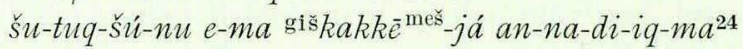

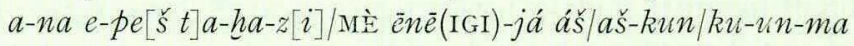

a-na šul-lu-mu qi-bit dNannari ${ }^{\text {ri25 }}$ man-nu at-ta

šá a Sin a-na šarru-u-tiltui i-nam-bu-ka-ma

māru-ú $-u_{8}{ }^{?}{ }^{?}-a-m a^{26} i-q a b-b u-k a$ aś-rat d $S \hat{i n}{ }^{27}$

$a$-šib šá-ma-me šá? q[i-bit-su la in-ne $] n-n u-u$

u a-mat-su la ta-[qab-bu-] $u$ šinī(II)-š $u$

40

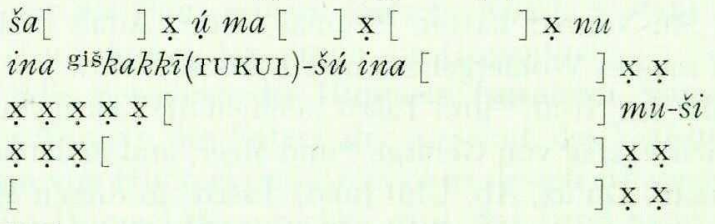

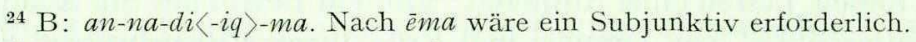

${ }^{25} \mathrm{~B}$ hat offenbar d ̌̌šs. $\mathrm{x} \times \mathrm{KI}^{r i}$, Rasur wegen eines Schreiberversehens oder Fehler im Stein? Moran (a. a. O. I40): đŠĔ̌K $[\mathbf{I} e] g$-di-ri.

${ }^{26}$ Lies so? Unsicher. B weicht $\mathrm{ab}$, ist aber ebenfalls schlecht lesbar. $i$-nam-bu$k a[-m a]$ x $m \bar{a} r u-u-j a ́-a ?-m a$ ?

27 Text B bricht hier ab. Es erscheint mir recht unwahrscheinlich, daß , the mason preferred to have a handsomely-finished work rather than to mar it by a pedantic insistence upon completeness" (Gadd, S. 44). Man darf wohI vermuten, daß der Text (ca. 7 Zeilen fehlen noch) auf dem Basisstein beendet wurde. Die Schmalseiten der Stele sind jedenfalls nicht beschrieben. 
(I) ${ }^{1}$ Die große Tat des Sîn, die 〈von〉 den Göttern und Göttinnen ${ }^{2}$ keiner weiß, die seit fernen Tagen ${ }^{3}$ nicht zum Lande gekommen ist; die Bewohner des Landes sahen (sie) 〈nicht〉, und ${ }^{4}$ man hat (sie) nicht auf eine Tafel geschrieben und ${ }^{5}$ für künftige Tage ${ }^{4}$ nicht niedergelegt. ${ }^{5}$ Sîn, Herr der Götter und Göttinnen, der Bewohner ${ }^{6}$ des Himmels, der du vor Nabonid, den König von Babylon, ${ }^{7}$ vom Himmel her kamst, (du tatest sie).

Ich bin Nabonid, 8einziger [Soh]n, der niemanden hat, dem die Königsherrschaft ${ }^{9}$ nicht im Sinn lag. Die Götter und Göttinnen ${ }^{10}$ beteten für mich, und Sîn ${ }^{11}$ berief mich ${ }^{10}$ zur Königsherrschaft. ${ }^{11} \mathrm{Zur}$ Nachtzeit ließ er mich einen Traum sehen, ${ }^{12}$ (wobei er?) folgendermaßen (sprach): „Ehulhul, den Tempel des Sîn in Harrān, ${ }^{13}$ errichte eiligst. Alle Länder will ich dir in die Hand ${ }^{14}$ geben."

Die Leute, Bürger von Babylon, Borsippa, ${ }^{15 N i p p u r, ~ U r, ~ U r u k, ~}$ Larsa, Priester, ${ }^{16 / 17}$ Leute von den Wohnstätten Akkads verfehlten sich gegen seine große Gottheit und frevelten verächtlich ${ }^{18}$ in Unkenntnis des furchtbaren Zornes des Königs der Götter Nannar. ${ }^{19} \mathrm{Sie}$ vergaßen ihre Riten und sprachen Lügen ${ }^{20}$ und Unwahrheiten. Wie Hunde fraßen sie einander. ${ }^{21}$ (Kopf)krankheit und Hunger ließen (die Götter) unter ihnen ${ }^{22}$ entstehen, er (Sîn ?) verminderte die Leute des Landes.

Ich aber, ${ }^{23}$ aus meiner Stadt Babylon ließ er mich fliehen, und ${ }^{24} \mathrm{den}$ Weg (nach) Tēmā, Dadanu, Padakku, ${ }^{25} \mathrm{Hibra}$, Jadiḩu bis nach Jatribu (schlug ich ein). ${ }^{26}$ Io Jahre lang bin ich zwischen ihnen herumgezogen, ${ }^{27}$ meine Stadt Babylon betrat ich nicht.

Auf das Wort des Sîn, ${ }^{28}$ des Königs der Götter, Herrn der Herren, das die Götter und Göttinnen, die Bewohner ${ }^{29}$ des Himmels, ausführen, auf Befehl des Sîn-Nannar hatten ${ }^{30}$ Šamaš, Ištar, Adad und Nergal auf den Schutz meines Wohlergehens und Lebens ${ }^{31}$ acht.

In diesem Jahr, im Nisān ${ }^{32}$ und Tašrìt nehmen die Leute von Akkad und Hatti reichen Ertrag von Gebirge ${ }^{33}$ und Meer, und in der schweren Hitze ${ }^{34}$ von Simān, Du’ūz, Ab, Ulūl (und) Tašrìt, in diesen Monaten, ${ }^{35}$ in allen diesen Jahren ohne Aufhören ${ }^{36}$ gibt auf Befehl des Sîn Adad, der 'Kanalinspektor' von Himmel und Erde, ihnen ${ }^{37}$ Regenwasser zu trinken. Ihre Habe und ihr Besitz ${ }^{38}$ kommt in Frieden(?) bei mir ein.

Auf Befehl des ${ }^{39}$ Sîn ${ }^{41 / 42}$ breitete(?) auch ${ }^{39}$ Ištar, die Herrin der Schlacht, ohne die es Feindschaft und Friedensschluß ${ }^{40} \mathrm{im}$ Lande nicht gibt und kein Krieg ${ }^{41}$ geführt wird, ihre Hand über sie, ${ }^{42}$ und der König von Ägypten, Medien, ${ }^{43}$ das Land der Araber und alle feindlichen Könige ${ }^{\mathbf{4} 4}$ schickten (Boten) zu Friedensschluß und Versöhnung ${ }^{{ }^{4}{ }^{2} \mathrm{zu}}$ mir. 
Die Leute von Arabien, die $\mathrm{x} \times \mathrm{x}{ }^{46} \mathrm{x} \times \mathrm{x} \times$ [ ] des Landes Akkad ${ }^{47}$ und(?) $\mathrm{x} \times \mathrm{x}$ [ ] x x um zu ${ }^{48}$ rauben und wegzunehmen(? ?) die Habe traten sie hin(?). (II) ${ }^{1}$ Auf das Wort des Sîn zerbrach Nergal ihre Waffen ${ }^{2}$ und sie beugten sich alle unter meine Füße.

${ }^{3} \breve{S}$ amaš, Herr des Orakels, ohne den kein Mund ${ }^{4}$ geöffnet und kein Mund geschlossen wird, ${ }^{5}$ indem er den Befehl des Nannar, des Vaters, der ihn schuf, ausführte, ${ }^{6}$ den Leuten von Akkade und Hatti, die er in meine Hände gegeben hatte, ${ }^{7}$ denen setzte er einen mir treu (ergebenen) Mund und Herz, ${ }^{8}$ und sie halten meine Wache, ${ }^{9}$ befolgen meinen Befehl im Bereich ${ }^{10}$ entfernter Gebiete, dem 'Irrweg', den ich ging.

${ }^{11}$ (Nach) Io Jahren trat der Zeitpunkt ein, ${ }^{12}$ wurden die Tage voll, die der König der Götter Nannar gesagt hatte, ${ }^{13}$ im Monat Tašrit am I7. Tage. 'Tag, (an dem) Sîn willfährig ist', ${ }^{14}$ ist seine (ominöse) Bedeutung.

Sîn, Herr der Götter, dessen Name am I. Tage ${ }^{15}$ 'Sichel(?) des Anu' ist, — in den Himmel greifst du ein ${ }^{16}$ und die Erde zerbrichst du, - der vereinigt die Kultsatzung ${ }^{17}$ der Anuschaft, zusammenfaßt die Kultsatzung der Enlilschaft, ${ }^{18}$ (in Besitz) nimmt die Kultsatzung der Easchaft, ${ }^{19} \mathrm{der}$ die Gesamtheit der Kultsatzungen des Himmels in seinen Händen ${ }^{20}$ hält, Enlil der Götter, König der Könige, Herr der Herren, ${ }^{21}$ der seinen Befehl nicht wiederholt ${ }^{22}$ und dessen Wort nicht zweimal gesagt wird, ${ }^{23}$ vor dessen großer Gottheit Himmel ${ }^{24}$ und Erde voll Furcht sind so wie Himmel ${ }^{25}$ und Erde mit seinem Glanz bedeckt sind. Jeder, der ohne dich ist, ${ }^{26}$ was tut er ? Ein Land, in dem dein Herz zu wohnen ${ }^{27}$ trachtet, dem legst du die Furcht vor deiner großen Gottheit ${ }^{28}$ ins Herz, und auf ferne Tage hin ${ }^{29}$ sind seine Fundamente fest. Ein Land, das dein Herz ${ }^{30} \mathrm{zu}$ zerstören trachtet, dem entfernst du die Furcht vor dir ${ }^{31}$ aus seinem Herzen, wirfst es ${ }^{32}$ auf ferne Tage hin nieder. (Du,) dessen Ausspruch die Gesamtheit der Götter und Göttinnen, ${ }^{33}$ die Bewohner des Himmels, bewahren, ${ }^{34}$ ausführen den Befehl ${ }^{35}$ des Nannar, des Vaters, der sie schuf, des Vollenders ${ }^{36}$ der Kultsatzungen von Himmel und Erde, ohne dessen erhabenen Befehl, ${ }^{37} \mathrm{der}$ täglich im Himmel ${ }^{38}$ gesprochen wird, das Land nicht gegründet wird ${ }^{39}$ und kein Licht im Lande ist. ${ }^{40}$ Die Götter beben wie Rohr, es erzittern ${ }^{41}$ die Anunnaki, die vor dem Befehl seiner ${ }^{42}$ großen Gottheit, der nicht [geändert] wird(?) x x des Gebirges(?) .... (Reste von ca. 8 Zeilen ohne sichere Lesung und Deutung).

(III) ${ }^{1} . . . \ldots$, das Omen des Opferschaupriesters 2 (und) des Traumdeuters unterbrach den Weg nicht, ich lag da und ${ }^{3}$ inmitten der Nacht war der Traum beängstigend bis das Wort [du sprachst??]. ${ }^{4}$ Voll wurde das Jahr, der Zeitpunkt, den [Sîn genannt hatte(?)] trat ein, ${ }^{5}$ von 
Tēmā [ließ er mich herausgehen(?)], ${ }^{6}$ Babylon, [meine] Residenz [suchte ich auf(??) ] ${ }^{7}$ sahen sie und $\mathrm{x} \times \mathrm{x}[\mathrm{I}$ [ ] $\mathrm{x}$ ${ }^{8}$ Versöhnungsgeschenke(?) brachten sie $\mathrm{zu}\left[\operatorname{mir}\left(\right.\right.$ ?) ] ${ }^{\mathbf{9}}$ ] ] x x x Die Könige aus der Nähe ${ }^{10} \mathrm{kcmmen}$ herauf und küssen meine Füße ${ }^{11}$ und die in der Ferne hörten es, fürchteten seine große Gottheit. ${ }^{12} \mathrm{Götter}$ und Göttinnen, die erschreckt waren und sich entfernten, ${ }^{13}$ kehrten um und sprechen Gutes für mich, ${ }^{14}$ und in derEntscheidung(?) des Opferschaupriesters wurde das Opferschawomen mit guter Bedeutung für mich gesetzt. In Reichtum ${ }^{15}$ und $F$ ülle und Überfluß leitete ich meine Leute in den entfernten Berg(ländern) ${ }^{16}$ beständig, und in Wohlbefinden schlug ich den Weg ${ }^{17}$ nach meinem Lande ein.

Das Wort seiner großen Gottheit bewahrte ich und ${ }^{18}$ wurde nicht müde, war nicht pflichtvergessen, war nicht nachlässig, sondern ich ließ ${ }^{19}$ die Leute von Akkade und Hatti ${ }^{18}$ aufbieten, ${ }^{19}$ von der Grenze Ägyptens ${ }^{20}$ am oberen Meer bis zum unteren Meer, die Sîn, der König der Götter, ${ }^{21}$ in meine Hand gegeben hatte: Ehulhul, den Tempel des Sîn, ${ }^{22}$ machte ich neu, vollendete die Arbeit daran. Die Hände des Sîn, ${ }^{23}$ der Ningal, des Nusku und der Sadarnunna von ${ }^{24}$ Suanna, meiner Residenz, ergreife ich, und unter Freude ${ }^{25}$ und Jauchzen ließ ich (sie dort) eintreten und ließ (sie) ein ewiges Göttergemach bewohnen. ${ }^{26}$ Gewaltige Opfer libierte ich vor ihnen und ${ }^{27}$ machte meine Geschenke reich. Ehulhul ${ }^{28}$ füllte ich mit Jauchzen und ließ das Herz seiner Bediensteten jauchzen. ${ }^{29} \mathrm{Ich}$ führte den Befehl des Sîn aus, des Königs der Götter, Herrn der Herren, ${ }^{30}$ des Himmelsbewohners, dessen Name den der Götter des Himmels übertrifft, ${ }^{31}$ des Šamaš, der ....., Nusku, Ištar, Adad, Nergal, ${ }^{32}$ die den Befehl des Nannar, ${ }^{33}$ der sie übertrifft, ${ }^{32}$ ausführten. ${ }^{33}$ Wo immer ich meine Waffen anlegte und ${ }^{34}[\mathrm{mich}] \mathrm{zu}$ [käm]pfen anschickte, ${ }^{35}$ (geschah es,) um den Befehl des Nannar zu erfüllen.

Wer du auch seist, ${ }^{36}$ den Sîn zum Königtum beruft und ${ }^{37}$,, mein lieber Sohn" zu dir spricht, das Heiligtum des Sîn, ${ }^{38}$ des Himmelsbewohners, [dessen Befehl nicht geändert] wird ${ }^{39}$ und dessen Wort nicht zweimal ge[sagt wird], ${ }^{40} \mathrm{der}[\mathrm{E}] \mathrm{x} \times \mathrm{x}[\mathrm{J}[\mathrm{x} \times \mathrm{x}$ ${ }^{41}$ mit seiner Waffe(?) in ... (Z. $42-44$ nicht zu entziffern).

\section{Bemerkungen zur Übersetzung}

I If.: Zur Übersetzung s. schon W. L. Moran, OrNS 28, I38. Die Präposition ina, die bei mamman , wer auch immer" mit pluralischem Objekt obligatorisch ist (vgl. z. B. mamman ina iläni ul iššannan itti-ka „,keiner der Götter ist dir vergleichbar" KAR I05, 6 u. ö., besonders in Königsinschriften), scheint nach Photographie und Abklatsch auf 
beiden Stelen zu fehlen. Die Aussage, daß die Taten des Mondgottes den übrigen Göttern verborgen bleiben, findet sich in ähnlicher Formulierung häufiger. Vgl. etwa: (Sîn) šá qí-bit-su la ut-tak-k[a-ru] $\dot{u}$ tè-en-šú ilu ma-am-ma la $i$-du-ú ,,(Sîn), dessen Ausspruch nicht geändert wird und dessen Befehl kein Gott weiß" E. G. Perry, LSS 2/4, 23,5 ; i-bí-eš-du gìr-ra šà-ab-sù-ud dimmer-na-me nu-mu-

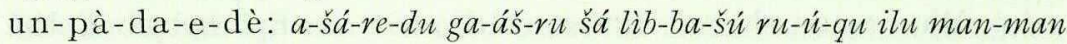
la ut-tu-u ,Allererster, Starker, dessen Inneres fern ist, kein Gott kann (es) durchschauen " IV R 9 I $36 \mathrm{f}$. = A. Sjöberg, Nanna-Suen I (I960) I67, I8; ...e e-ne-èm-zu ... ám-na-me nu-mu-un-pà-da-e-dè: ... a-mat-ka ... šá man-ma-an la ut-tu-u ,... dein Wort ..., das niemand durchschauen kann" ebd. II $7 \mathrm{f}$. = ebd. I68, 33; 'Namrașît ... šá la i-lam-ma-du mi-lik-šú ma-a[m-man] ,Namraṣit ... dessen Ratschluß niemand erfährt" E. Ebeling, AGH 6, I9. Die gleiche Aussage gibt es aber auch von anderen Göttern, z. B. Ištar, s. KB 6/2, I28, 39 .

I 3: tu-ri-du: Die Form weist unter aramäischem Einfluß (GAG $\$ 75 \mathrm{~h})$ das in der Inschrift öfter $z u$ beobachtende t-Präfix bei der 3. Pers. Sg. Fem. auf, s. tab-šu-ú I 9 ; ta-ap-ri-ik I 42; ta-an-na-du-u II 38. Vgl. den spB Brief UET 4, I82, 7 : ki-i it-ti-ka ta-ad-dib-bu tu-u$r i-d u \ldots s u p-r a$, so, wie sie mit dir gesprochen hat, heruntergekommen ist, ... schreibe mir." - Die Konjektur $\langle l a\rangle$ ip-pal-su-ma (Vorschlag von A. Falkenstein) ergibt sich aus dem Sinn des Abschnitts, der die Situation schildert, wie sie bei der Abwesenheit des Gottes von seinem Heiligtume entstanden war. Vgl, dagegen die Aussage in $\mathrm{H}_{3}$ I3f, (u. S. 248).

I $5 \mathrm{ff}$.: Auffällig ist der plötzliche Wechsel in die Anrede (vgl. auch II I5f.; 25-32), wie überhaupt der ganze Abschnitt I I-r4a mit seiner kurzen Berichterstattung ungewöhnlich stilisiert ist.

I 8 f.: Wörtlich: ,,der, (von dem gilt:) die Königsherrschaft lag nicht in meinem Sinn“. Vgl. šá šarru-ú-tú ina libbri-ja la ba-šu-ú VAB 4,280 (Nbn. Nr. 8) VII $47 \mathrm{f}$.

I I4: lu-mál-la: Wörtlich, füllen“, zur Lesung vgl. W. L. Moran, OrNS 28 (I959) I36. An allen von Moran aufgeführten Stellen steht allerdings, soweit sie deutlich sind, das Zeichen mál (DIR AnOr. 27 Nr. 89) mit dem charakteristischen gebrochenen senkrechten Keil am Ende.

I I7: S. W. L. Moran, a. a. O. I39 mit Verweis auf CAD G I32a, jetzt auch AHw. 297bf. gullulu Abs. 2.

I I9: $i$-dib-bu-bu: Lies wohl so; Präteritum entspr. den übrigen Formen, s. GAG $§ 18 \mathrm{~d} ; \mathrm{AHw}$. 147a. 
I 20: UR.GIR , obwohl ohne Pluralzeichen, doch wohl pluralisch aufzufassen, wie auch das häufige ${ }^{~} i$ štar (vgl. aber A III I2). - i-ta-na-kal: die Lesart von Exemplar B ist trotz der fehlenden Endung der Lesart $i t$-ta-nak-ka-lu von A vorzuziehen, die formal einen Ntn-Stamm (Passiv) bietet, was aber nach dem Zusammenhang sinnlos ist. Die präsentische Form wurde nach dem Zusammenhang präterital übersetzt. Wurden durch -tan- erweiterte Formen im Spätbabylonischen zuweilen in diesem Sinne gebraucht? Vg1. etwa at-ta-nab-bal-šú-nu-ši ,,ich brachte ihnen immer wieder dar" $\mathrm{VAB} 4,262,22$; ik-ta-na-ar-rabu šarrūtī , sie huldigten beständig meinem Königtum" ebd. 276, 6 .

I 2If.: Der ständige Subjektswechsel ist schwer zu erklären. Es ist kaum wahrscheinlich, daß die Babylonier noch Subjekt zu $u s ̌ a b s ̌ \hat{u}$ sind. Wegen der eindeutigen Pluralform kann aber auch Sîn, den man wohl als Subjekt der folgenden Verben voraussetzen muß (Moran, a. a. O. I38), nicht herangezogen werden.

I 23: Zum Verbum s. Moran, a. a. O. I38.

I 29: Lies mit B ú-šal-li-mu-u’ und s. Moran, a. a. O. I38f.

I 38: Die Lesung des Anfangs der Zeile ist nach den Abklatschen nicht sicher zu ermitteln. Parallele Ausdrücke kenne ich nicht (vgl. CAD E 265f.; AHw. 235 bf.).

I 39: Moran schlug vor (a. a. O. I39), hier das Verbum barāqu „,blitzen“ (AHw. I06a) einzusetzen, doch wird dies nur im Zusammenhang mit Adad gebraucht. Man wird also zu paräku zurückkehren müssen (s. Gadd, a. a. O. 67). Bei der dann möglichen Übersetzung , sie stellte ihre Hand ihnen entgegen“ fällt auf, daß kein Beziehungswort zu ana muhȟr-šsumu vorhanden ist, es sei denn, man sieht es in den im folgenden genannten Königen. In Verbindung mit qātu ist mir aus den Sammlungen zum AHw. nur noch ein mittelassyrischer Beleg bekannt, KAV I59, die Selbstverpflichtung eines Sklaven (s. NKRA 225). Der Schluß (Z. gf.) lautet: [q]a-tu ša bēlī-ja a-na muhnhi urdāni ${ }^{\text {mešs̆ }}{ }_{-s} u$ lu pár-ka-at, in der Übersetzung von O. Schroeder, ZA 34 (I922) I65: „,Meines Herrn Hand ist über seine Diener gebreitet(?)“. Ein ähnlicher Sinn dürfte auch an unserer Stelle vorliegen und ina muhhri-šunu auf die vorher genannten Bewohner von Akkade und Hatti zu beziehen sein. Ištar hält ihre Hand über sie, indem sie die Fürsten der umliegenden Länder veranlaßt, um Frieden zu bitten.

I 4of.: Zu kakka epēšu „Krieg führen“ s. CAD E 2 Ioa.

I $42 \mathrm{f}$.: Die Ausdrucksweise šàr māt Mișir uru Madāja māt Arabi ist höchst auffällig, zumal šàr wohl kaum auf alle drei Namen bezogen werden darf (s. Gadd, a. a. O. $76^{3}$ ). Während mät Miṣir und mät Arabi ohne Weiteres verständlich sind, bereitet uruMadäja schon wegen des 
Determinativs Schwierigkeiten. Belegt ist $\mathrm{m}$. W. bisher nur kUR oder Lú als Determinativ (vgl. z. B. R. P. Boudou, Orientalia 36/8 (I929) II5). Die Identifikation der ,Mederstadt" mit Ekbatana, der Hauptstadt des medischen Reiches (Gadd, a. a. O. 76), ist natürlich möglich und wahrscheinlich. Dennoch bleibt die Ausdrucksweise singulär, und es ist unklar, welcher historische Sachverhalt sich dahinter verbirgt. Die Meder werden von Nabonid sonst als Ummān-manda bezeichnet (vgl. dazu D. J. Wiseman, CCK I5f.), ihr Reich war aber zur Zeit der Abfassung von $\mathrm{H}_{2} \mathrm{~A} / \mathrm{B}$ (540/39) schon längst an Kyros gefallen (s. u. S. 257 f.), was von der Inschrift $\mathrm{Nbn}$. Nr. I (VAB 4, 2I8ff.), die in ihren Formulierungen große Ähnlichkeit mit $\mathrm{H}_{2} \mathrm{~A} / \mathrm{B}$ hat, also früher entstanden sein dürfte (s. u. S. 24I), auch berichtet wird. Die Angabe von $\mathrm{H}_{2} \mathrm{~A} / \mathrm{B}$ ist also entweder als Anachronismus aufzufassen, oder — was mir wahrscheinlicher ist - als Übertragung einer ethnischen Bezeichnung auch auf das nachfolgende Reich. Schließlich hatten auch Kyros und seine Nachfolger noch Ekbatana als zeitweilige Residenz. Vielleicht spielt sogar das Strophengedicht auf diesen oder einen ähnlichen Passus einer Inschrift an, wenn es darin übertreibend heißt: „Er (Nabonid) aber schreibt auf seinen Steintafeln: Ich habe ihn (Kyros) unter meinen Fuß gebeugt, seine Länder hat meine Hand erobert, seinen Besitz habe ich [nach meiner Residenz] gebracht" BHT 85 V 6 f. (= ZA 37 (I927) 92).

I $45 \mathrm{f}$.: Eine befriedigende Lesung dieser Zeilen ist leider nicht zu gewinnen. ${ }^{\text {giš }}$ TUKUL ist nach Text B ausgeschlossen, wo $d u(u s ̌$ ?) $\check{s} u$ ? $\mathrm{x}$ zu erkennen ist. Am Anfang von Z. 46 ist GAL sicher, davor wahrscheinlich $i \check{s}$. W. von Soden verweist mich dafür auf das Verbum šuqallulum ,,hängen, schweben", das aB oft, jB selten den Präfixvokal $i$ - hat (GAG $\$$ Iog g). Vgl. šumma atãnu tülid-ma šìrēmeššsú išqá-lal-la ,,wenn eine Eselin geboren hat, sein (des Jungen) 'Fleisch' herabhängt" TU 8, I6, Dpl. CT 40, 33, I8, Dpl. LKU I24 Rs. Io (Var. $u \check{s}-q a^{\prime}-l a l-l a$, s.W. von Soden, OLZ I933, 5I8).

II Io: urhu pariktu: Zur Bedeutung „Irrweg“, allerdings in einem wie im Deutschen schillernden Sinne, führen die Belege für das Adjektiv parku, die mir aus den Sammlungen zum AHw. zur Verfügung standen. parku $(m)$ wurde von B. Landsberger, MSL I, I63 in $x i k u$ pa-ar-kum (TCL II, 236, I8) als terminus technicus, gegen die Furchenrichtung gepflügt" bestimmt. Allgemein trifft etwa die Übersetzung ,,über Kreuz, quer" zu, wobei die Abgrenzung gegen egru (s. AHw. Igob; CAD E 47) nicht recht klar ist. In Omina heißt es etwa: šu-ul-mu pa-ar-ku ša-ki-in , die Blase(?) liegt quer" CT 4, 43 b 4 ; ${ }^{\text {giš }} k a k k u$ pár-ku šakin , die 'Waffe' liegt quer" CT 3I, 3 IV 9, vgl. 5 III 53. Häufiger be- 
gegnet hier das Adverb parkiš: [šumma bā]b ekallim pa-ar-ki-iš e-și-ir ,"wenn das 'Pa]lasttor' quer gezeichnet ist" YOS I0, 22, I6; ușurtu pár-kiš/GIL-iš eşret ,.... eine Zeichnung quer (darauf) gezeichnet ist" TCL 6, 5, 22; KAR I53, I9; BRM 4, I2, 58. 6I-66, vgl. AGS 85 Rs. 4. Gegensatz: išariš esret, z. B. RA 44, I6, 4. Zur Herstellung eines astronomischen Instrumentes heißt es usurta pa-rik-ti $a$-di šá-pa$a$-ti te-es-ṣer ,einen Querstrich wirst du bis zu den Rändern ziehen“ LBAT I495, 6 vgl. I494, 2-4. 8. I0. Rs. 3; I495, I4 (P1. usurāti $p a-a ́ r-k e-e-t i)$. Das substantivierte Femininum hat dann gemäß dem Gegensatz išarum , gerade, recht" - parkum ,,verquer, unrecht" die Bedeutung „Unrecht" angenommen, vgl. niše ket-ta u-maš-ši-ra-ma iṣ-ba-ta pa-rik-ta, ,die Leute verließen das Recht, 'packten' das Unrecht" Erra IV 73; ša eqlèt mārē Bābili ... ina pa-rik-teltú it-ba$l u(-u)-m a \ldots$, der die Felder der Einwohner von Babylon ... zu Unrecht weggenommen (und sich angeeignet) hatte" Ash. Nin. A III 65; šá annanna apil annanna pa-rik-ta-šu li-šir ,möge das Unrecht, das an NN, Sohn des NN (begangen wurde), in Ordnung kommen" KAR I92 IV 9 (s. CAD E 355 b) ; 'Šamaš . . ina pa-rik-ti li-iz-zis-su, , ک̌amaš . . . möge mit Unrecht $\mathrm{zu}$ ihm treten" I R 7 III I5-I7 (= KB 4, 80 III I5-I7); BBS: 8 IV rof. Aus der gleichen Fluchformel eines mittelbabylonischen Kudurru stammt auch ein Beleg für harrāmu pariktu: Anu rabû bèlu rabû har-ra-an-na pa-ri-ik-ta li-še-es-bi-su ,,Möge ihn der große Anu, der große Herr, einen Irrweg einschlagen lassen" BBS: 8 IV 3of. Die Wendung muß also etwas Negatives beinhalten. Entsprechend wird das Gegenteil mit harrānu išartu bezeichnet: (Marduk) ha-ra-na $i$-šar-tú ta-pa-qid-su ,einen geraden Weg bestellst du ihm“ VAB 4, 122, 60. Allerdings ist es wenig wahrscheinlich, daß Nabonid an der Stelle, von der wir ausgingen, sein eigenes Unternehmen als einen Fehlschlag bezeichnet, vielmehr dürfte parallel zu ina pirik šad nesüti an Irrweg im Sinne von ,Weg durch die Wildnis, Wüste“ zu denken sein. (Unklar bleiben mir die neuassyrischen Belege für parku KAV 2I3, 27; ABL I32 Rs. 4.)

II II: Vg1. Gadd, a. a. O. $88^{1}$, unten Kol. III 4 und beachte $a$-daan-mu ik-šu-da-am-ma up-ta-at-ta-a-ni bābāni ${ }^{m e s ̌ ~, ~ d e r ~ Z e i t p u n k t ~ t r a t ~}$ ein, die Pforten wurden mir aufgetan" YOS I, 45 I 28 (= SD 2 , I64, 28); im-lu-ú ūme $e^{-\mathrm{meš}} i k-s ̌ u-d a$-dan-nu, ,erfüllt waren die Tage, der Zeitpunkt trat ein (der Zorn des Götterherren ... legte sich)" Nbn. Nr. $8=V_{\text {VAB }}^{4}, 270$ I $26 \mathrm{f}$; $u_{4}$-me im-lu- $i$ ik-šú-da a-dan-na Iraq ${ }_{5}$ (I953) I23, Io (Marduk-apal-iddina II.); s. R. Borger, Ash. S. I5.

II I4: pišru, eigentlich ,,(Auf)lösung““. Zum Terminus vgl. zuletzt A. L. Oppenheim, Dreams S. 220 (,,solution“); ferner E. F. Weidner, 
BA 8/4, 5; G. Meier, OrNS 8 (I939) 306. Gadds Deutung als „, revelation" ist kaum haltbar. Der Nominalsatz erhält eine Erklärung des vorher genannten Datums gemäß den Hemerologien (s. u. Anm. 99).

II I5: Das erste Zeichen der Zeile ist zweifellos ku. Weder die Deutung Gadds (mittu, a. a. O. S. 68) noch die Morans (Sin, OrNS 28 (1959) 139) kann befriedigen. Es muß askar d $A$-nù gelesen werden (W. von Soden). Allerdings hat askaru/uskaru ,Sichel" das Wortzeichen UD.SAR, doch weisen alle Indizien auf die vorgeschlagene Deutung. Vgl. [šumma S] în ina tāmartī-šu ultu UD I KAM adi UD 5 KAM $5 u_{4}$-mi askar (UD.SAR) d $A-n u-u m$, [Wenn S] în beobachtet werden kann (heißt er) vom I. bis zum 5. Tage, 5 Tage lang, 'Sichel des Anu'“" E. F. Weidner, HBA I8, 4 (= KB 6/2, 94 b If.); tàmarti UD I KAM askar(UD.SAR) d A-nim, ,(Bei der) Beobachtung am I. Tage, 'Sichel des Anu'“ CT 25, 50, I; 'Sin Ud.SAR! šamêe ù erseti ${ }^{t i}$,, Sîn, Sichel von Himmel und Erde" BE I, I49 III 6 (= BER 4, I92 III 6); ina šumèti-ja ¿Sin UD.SAR šamêt rabütimeš ,zu meiner Linken Sîn, die Sichel der großen Himmel" KAR I84 Rs. 46 (= TuL 86, 46).

II I6ff.: Die Aussage, daß der Mondgott alle 'me' (parșu) auf sich vereinigt, findet sich bereits im Sumerischen, vgl. A. Sjöberg, NannaSuen I (Ig60) 35, 5-8 mit Kommentar.

II $24 \mathrm{f}$ : Vgl. Moran, a. a. O. I39. Zu zìmu ,Glanz, Glut" von Mond und Sternen s. CAD Z I2I b.

II 3I : -mu für die enkl. Kopula -ma ist auch sonst gelegentlich zu beobachten, s. F. Thureau-Dangin, RA 32 (I935) Iogf.; GAG § I23a. Besonders oft in der Inschrift Sargons II. YOS I, 38 I Ig. 20. 22. II 23. 34. - Beachte, daß nasû hier transitiv ist, vgl. W. Muss-Arnolt, Handwörterbuch S. 697 a (selten).

II 36: a-bal, vgl. Moran, a. a. O. I39 zur Stelle.

II 38: Das Verbum nad̂, das in Z. 3 I im Sinne von ,,niederwerfen“ verwendet wurde, muß hier dagegen die Bedeutung ,gründen" haben. Vgl. z.B. Io urubi-ra-a-ti dan-nu-ti . . ad-di-ma, ,Io starke Festungen ... gründete ich" Sg. Lie 36, 216; s. Muss-Arnolt S. 646f., ferner genau parallel: Sîn ... šá ul-la-nu-uš-šu àlu ù mātu la in-nam-du-ú la i-tur$r u$ áš-ru-ušs šu ,Sin, ... ohne den Stadt und Land nicht gegründet, nicht wiederhergestellt werden" $\operatorname{VAB}_{4}, 222,26 \mathrm{f}$. (Nbn. Nr. I).

II 40: Ergänzung nach einem Vorschlag von W. von Soden. Vgl. die fast identische Zeile AGH I30, 2I, Dpl. KUB 37, 36 r 21 : ilāni meš $i$-šub-bu i-nar-ru-ṭuttù d A-nun-na-ki/ku$u_{13}$. Zu šâbu s. R. Borger, Ash. S. $57^{81}$. Das Ende der Zeile bleibt sehr unsicher.

III I-3: W. G. Lambert hat in BWL S. 284 darauf aufmerksam gemacht, daß diese Zeilen ein Zitat aus Ludlul I 52 und 54 sind und hat 
die entsprechende Lesung geboten (s. auch BWL S. 288: K. 2765, 7. 8). Leider ist die Deutung der Zeilen nicht ganz eindeutig, vgl. BWL S. 284; R. Frankena, BiOr. I4 (I957) 9a; AHw. 3I a zu alakta parāsu. Das Ende von Zeile 3 ist nach II I2 sinngemäß ergänzt.

III 8f.: An den Originalen dürften für diese Zeilen noch bessere Lesungen zu erzielen sein.

III I2: ip-par-du, zum Verbum s. Moran, a. a. O. I39f. Auffällig ist das Präteritum des N-Stammes, der sonst $m$. W. nicht belegt ist. Die Lesung $i p-r u$ :- $d u$ verbietet Exemplar B.

III 26: Zur Lesung vgl. die genau entsprechende Partie in Nbn. Nr. I ( $\left.=\operatorname{VAB}_{4}, 222,22\right)$ und zu nīqê taš-ri-ih-ti/te auch Sg. 8, I6I; Ash. Nin. A VI 46; 48 , I5; Asb. A X 106; Sn. 98, 92; I16, 69; 125, 50 u. ö.

III 28: ušāliṣ libbi nišé-šu kann nach der Parallele in Nbn. Nr. I (= $\mathrm{VAB}_{4}, 222,23 \mathrm{ff}$.) auch auf die Bewohner von Harrān zu beziehen sein, doch wird die Stadt hier nicht besonders erwähnt.

III 3 : a S̆amaš šá ni-bu-šú, obgleich epigraphisch sicher, bleibt mir unverständlich. Man erwartet einen dem üblichen șit libbī-šu (bezogen auf Sîn, VAB 4, 224, 40; 226 II I2, s. StOr. 7, 454) entsprechenden Ausdruck.

III 33 f.: Vg1. AHw. I86b; CAD E 29 b und Moran, a. a. O. I40 zur Ergänzung nach parallelen Wendungen im Erra-Epos.

\section{Die Komposition der Inschrift}

Bereits S. Langdon bemerkte, daß mehrere der Inschriften Nabonids von dem herkömmlichen und auch von seinen Vorgängern angewendeten Schema abweichen. ,Seine Inschriften verraten, daß er Originalität und Sinn für Gelehrsamkeit in viel höherem Grade besaß, als irgend ein anderer babylonischer Herrscher" ${ }^{28}$. Dies gilt für die Inschriften aus Harrān in besonderem Maße. $\mathrm{H}_{1}$ enthält zwei Inschriftentypen, einen Teil, der an die sonstigen babylonischen Inschriften Nabonids erinnert, einen anderen, der sich an Formulierungen aramäischer Grabinschriften orientiert ${ }^{29} . \mathrm{H}_{2}$ tritt zwar im Gewand einer Bauinschrift auf, weicht jedoch in ihrem Schema ganz erheblich vom herkömmlichen Typus ab. Die Einleitung schließt mit dem Befehl zum Bau des Ehulhul. Danach wird der gesamte Bericht über den Aufenthalt des Königs in Tēmā eingeschoben. Schließlich wird knapp die

$28 \mathrm{VAB}_{4}, \mathrm{r}_{2}$.

29 B. Landsberger, H. Edhem Memorial I I35. 
Vollendung des Tempelbaus geschildert. Grob gegliedert läßt sich folgender Aufbau erkennen:

I. I I -22 :

a) Die große, allgemein noch nicht gewürdigte Tat des Sin, die sich in den folgenden Ereignissen offenbart ( $I$ I $\rightarrow$ )

b) Berufung Nabonids zur Königsherrschaft (I 7-II)

c) Traum mit dem Befehl zum Bau des Ehulhul (I II-I4)

d) Widersetzlichkeit der Babylonier (I I4-22)

2. I 22-II Io: a) Aufenthalt des Königs in Arabien unter dem besonderen Schutz des Sîn (I 22-3I)

b) Adad spendet auf Befehl des Sîn fruchtbaren Regen (I 3I-38)

c) Ištar führt auf Befehl des Sîn die Unterwerfung feindlicher Fürsten herbei (I 38-45)

d) Nergal zerbricht auf Befehl des Sîn die Waffen der Araber (I 45-II 2)

e) Šamaš bewirkt auf Befehl des Sîn die Ergebenheit aller Untertanen (II 3-IO)

3. II II -III 3: a) Das Ende des zehnjährigen Aufenthaltes in Tēmã tritt an einem ominös günstigen Tage ein (II I I bis I4)

b) Gebet an Sîn (II I4-III 3)

4. III 4-44: a) Rückkehr nach Babylon und Huldigung der Fürsten (III 4-I7)

b) Einlösung des Versprechens an Sîn und Bau des Ehulhul (III I7-35)

c) Segen- und Fluch(?)formel (weitgehend zerstört) (III 35-44)

W. L. Moran hat überzeugend nachgewiesen, daß der Bericht vom Bau des Ehulhul in VAB 4, 2I8-224 (Nbn. Nr. I I-III) formal enge Beziehungen zur vorliegenden Inschrift aufweist, die kaum zufällig sein können. ${ }^{30}$ Er kommt zu dem Schluß, daß beide Texte auf eine gemeinsame Vorlage zurückgehen müssen, daß aber in $\mathrm{H}_{2}$ noch der Bericht über den Aufenthalt in Tēmā eingefügt wurde. Diese Erweiterung ist allerdings so erheblich, daß der klare Aufbau der Inschrift Nbn. $\mathrm{Nr}$. I vollkommen verwischt ist.

Im Folgenden sollen an Hand der durch den Aufbau der Inschrift gegebenen vier Abschnitte einige Fragen, die sich aus der neuen Inschrift hinsichtlich der Regierung Nabonids stellen, untersucht werden.

30 OrNS 28 (I959) I30-I35. 


\section{Die Herkunft Nabonids. Babylonische Reaktion}

Der Text beginnt mit einem Lobpreis der , großen Tat des Sîn", zweifellos der Errichtung des Tempels Ehulhul in Harrān, an dem sich die Inschrift ja befand. ${ }^{31}$ Die Urheberschaft des Mondgottes wird also behauptet, so wie dies auch die ,Überschrift" auf einem Sammelzylinder tut, auf dem sich Bauinschriften von den Šamaš-Tempeln in Sippar und Larsa, der Ištar von Akkade und der Anunitu befinden. Auch da heißt es: ,Die Tat des Sîn, des Herren der Götter und Göttinnen von Himmel und Erde, die ich für spätere Geschlechter zum Lesen auf Stelen ... aufschrieb“32. Das Thema der Inschrift, der Tempelbau, klingt also gleich in der ersten Zeile an. Die Betonung des Umstandes, daß Sîns Tat ,,seit fernen Tagen nicht zum Lande gekommen" sei, ist sicher im Zusammenhang mit $\mathrm{H}_{1} \mathrm{~B}$ I $7 \mathrm{f}$. zu verstehen, wo es heißt: ,,Sîn, der König der Götter, zürnte seiner Stadt und seinem Tempel, stieg zum Himmel hinauf "33. Das Ereignis im I6. Regierungsjahre Nabupolassars, auf das dieser Satz anspielt, ist uns durch die Chronik gut bekannt: Es ist die Einnahme und Plünderung Harrāns durch die vereinigten Heere der Babylonier und Meder (6IO v. Chr.), der auch der Tempel zum Opfer fiel ${ }^{34}$. Es ist auffällig, daß die Chronik auch der Plünderung des Tempels Erwähnung tut, was nur noch anläßlich der Eroberung von Ninive geschieht ${ }^{35}$. Es dürfte auch durchaus nicht die Regel gewesen sein, daß ein Hauptheiligtum in die Plünderung einbezogen wurde, vielmehr genoß es einen gewissen Schutz und seine Zerstörung galt als Frevel an der Gottheit ${ }^{36}$. Daß es

31 So die sicherlich richtige Vermutung von Gadd, S. 35 f.; 89 . Da die Rückseite aller Stelen unbearbeitet blieb, waren sie wahrscheinlich an die Wand gelehnt oder in sie eingelassen.

${ }^{32} \mathrm{CT}$ 34, 37, 79-8I (Dupl. Pl. $25 \mathrm{VI}$ ) : e-piš-tú a Sîn bēl ilānimeš ù diš-tar šá

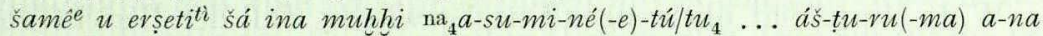

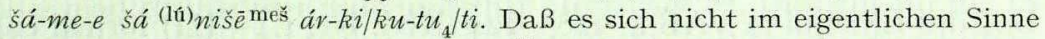
um einen Kolophon, sondern um eine Überschrift handelt, geht schon daraus hervor, daß die Zeilen beim Zylinder I912-7-6,2 nicht am Ende des Textes, sondern in einem freien Raum von Kol. II stehen. Es ist für die religiöse Haltung Nabonids recht aufschlußreich, daß die Urheberschaft des Mondgottes auch bei diesen Tempeln des Šmaš und der Ištar behauptet wird.

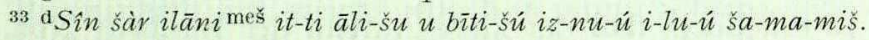

${ }^{34} \mathrm{CCK} 60 / 2,58-65$, vgl. Z. 64 : šil-lat āli u ekurri kabittutú iš-ta-lal ,die gewichtige Beute von Stadt undTempel erbeutete er (d.i. der König von Akkade) ".

35 CCK 6o, 45 .

${ }^{36}$ Vgl. schon die Klage um Lagaš F. Thureau-Dangin, SAK $56 \mathrm{ff}$. Für TukultīNinurta s. W. von Soden, Herrscher im Alten Orient (1954) 74; Sanherib ebd. S. I Io und die Darstellung Nabonids in der Hille-Stele VAB 4, $270 \mathrm{ff}$. Auch die Schuld an der Zerstörung des Heiligtums in Harrān schiebt Nabonid 
in Harrān dennoch geschah, dürfte seinen Grund wohl in der bevorzugten Stellung haben, die der Mondgott dieser Stadt unter den letzten Sargoniden innehatte, die dort sogar gekrönt wurden ${ }^{37}$. So ist es verständlich, daß man diesen bevorzugten Kult zu beseitigen trachtete, was bis zur Zeit Nabonids schon deshalb gelang, weil Harrān lange Zeit in den Händen der Meder blieb ${ }^{38}$. Um so auffälliger ist es, daß gerade der Sîn von Harrān von Nabonid ganz besonders bevorzugt wird. Es wird also nicht verwundern, daß hauptsächlich auf diesen Punkt die Kritik der Babylonier an der Politik des Königs konzentriert ist.

Der Abschnitt mit der Einführung des Königs und seiner Berufung zur Herrschaft ( $\mathrm{I}$ b $\mathrm{b}-\mathrm{II}$ a), obgleich zum festen Bestand jeder Königsinschrift gehörig, wirkt an dieser Stelle eingeschoben und gleichsam als eine Erklärung des Vorhergehenden. Nachdem bereits in Z. 6 der Name des Königs gefallen ist, wird er jetzt näher erläutert. Löst man den Abschnitt heraus, so ergibt sich - allerdings mit Wechsel von der 2. in die 3. Person - ein Handlungsablauf: Sîn kommt zum König und läßt ihn einen Traum sehen.

Nabonid nennt hier keine Genealogie, betont vielmehr, daß er ohne Beistand und ohne selbst damit gerechnet zu haben, von Sîn durch die Fürbitte der Götter als König eingesetzt wurde. Das ist frommer Betrug, denn wir wissen jetzt, daß jedenfalls seine Mutter nicht ohne Einfluß auf seine Karriere blieb. Die Inschrift der Adad-guppi ${ }^{39}$ $\left(\mathrm{H}_{1} \mathrm{~A} / \mathrm{B}\right)$ - wenn auch nach ihrem Tode von Nabonid gesetzt - liegt

allein den Medern zu (VAB 4, 2I8, I2) und stellt die Beteiligung von Babyloniern bei der Plünderung von Tempeln überhaupt in Abrede (VAB 4, 274 II 32 ff.). Daß jedenfalls die Götter aus Harrān zum Schutze nach Babylon geführt wurden, bestätigt auch unsere Inschrift (Kol. III 22-25), vgl. ferner H. Lewy, AIPHOS 13 (I953) $242^{3}$.

37 ABL 923. Vgl. J. Lewy, HUCA I9 (1945/6) 405-489; H. Lewy, ArOr. I7/2 (1949) $36^{38}$.

$38 \mathrm{Vgl}$. VAB 4, $218-220$. Unten S. $257 \mathrm{f}$.

${ }^{39}$ Der Name der Mutter läßt sich leider nicht befriedigend erklären (vgl. C. J. Gadd, AnSt. 8 (I958) 54). Er ist jedenfalls nicht akkadisch, und es spricht vieles dafür, daß er aramäischen Ursprungs ist. Mit den wenigen aramäischen Wörtern mit den Radikalen GP, die auch Gadd anführt, läßt sich nichts anfangen. Man könnte - im Anschluß an das von W. von Soden, AfO I9 (I960) I 49 beschriebene Phänomen, daß aram. $h$ spätbabylonisch als g wiedergegeben werden kann - an die Wurzel HPP/' denken, die pal.aram. und syrisch die Bedeutung, ,bedecken, darüberbreiten", Piel (Pael) auch ,, beschützen" hat. Allerdings paßt die Bedeutung nicht sonderlich gut, und es sind mir keine Namen mit diesem oder einem ähnlichen Element nachweisbar, so daß wohl auch diese Möglichkeit ausscheidet. 
jetzt wesentlich vollständiger vor als vor I5 Jahren und erlaubt manche interessante Rückschlüsse.

Volle Bestätigung findet die Feststellung B. Landsbergers und J. Lewys, daß die Mutter Nabonids keine Priesterin des Mondgottes gewesen sein kann. Sie spricht nur allgemein davon, daß sie von Jugend an (ultu meșherüti) eine Verehrerin des Sìn und seiner Familie gewesen sei und ihre Trauer über die Zerstörung des Ehulhul durch Bußübungen zum Ausdruck gebracht habe. Ungeklärt bleibt weiterhin, wie ihre Verbindung zu Harrān aufzufassen ist. Nichts weist darauf hin, daß sie in dieser Stadt geboren wurde; es ist - trotz der „Grabinschrift" - wenig wahrscheinlich, daß sie hier beigesetzt wurde ${ }^{40}$. Allerdings wird man wohl annehmen dürfen, daß sie wenigstens einen Teil ihres Lebens hier verbrachte, vermutlich ihre Jugend ${ }^{41}$. Daß sie damals enge Beziehungen zum assyrischen Hofe (z. T. in Harrān selbst) unterhielt, ist nicht auszuschließen, doch waren sie, wie sich jetzt ergibt, nicht so innig und auf eine Wahrung der assyrischen Tradition bedacht, wie dies Landsberger zunächst annehmen konnte ${ }^{42} \cdot \mathrm{H}_{1} \mathrm{~B}$ Kol. II Ende spricht nicht von den assyrischen, sondern von chaldäischen Königen, deren Verehrung im Leben und im Tode der Adadguppi am Herzen lag. Es ist in der Tat überraschend, daß sie sich als einzige Bewahrerin des Totenkultes dieser Könige vorstellt. Der Ort in der Inschrift, an dem dies geschieht, nämlich kurz vor dem Bericht über ihren Tod und die damit verbundenen Zeremonien ${ }^{43}$, ist zweifellos (mit Landsberger) dahingehend $\mathrm{zu}$ erklären, daß sie analog $\mathrm{zu}$ den Ehren, die sie diesen Toten erwies, gleiche Ehrungen erwartete. Un-

40 Nichts weist darauf hin, daß der Leichnam von Dūr-karāšu, einem Orte oberhalb Sippar, wo Adad-guppi am 5. Nisan 546 v. Chr. starb (BHT II2, I3), nach Harrān überführt wurde. Die Wendung iškunū ina nișirti, ,man legte (den Leichnam) an einen verschwiegenen Ort" ( $\mathrm{H}_{1}$ B III I6) macht es sogar zur Gewißheit, daß diese Überführung nicht stattfand. Es fehlt auch, nach der Aufzählung all der kostbaren Grabbeigaben, die obligatorische Warnung vor Grabräuberei oder Beschädigung von Grab und Stele, die man erwarten sollte, wenn das Grab in der Nähe gewesen wäre.

41 Dies wird man wohl mit B. Landsberger, H. Edhem Memorial I 149, voraussetzen müssen, um eine Rechtfertigung für die Aufstellung ihrer Stelen gerade in Harrān zu finden, auch wenn das Argument, daß sie hier ihre letzte Ruhestätte fand, nach Anm. $4^{\circ}$ nicht mehr berechtigt ist. Dagegen ist die Angabe ta-nit-tú/ti uRU-ja $u$ diš-tar-já, die sich in beiden Stelen findet $\left(\mathrm{H}_{1} \mathrm{~A}\right.$ I I $8=\mathrm{B}$ I 26) mit an Sicherheit grenzender Wahrscheinlichkeit in tanittu it̄(!)-ja u ištav-ja zu verbessern. Wohl ein Hörfehler in der Vorlage. Vgl. schon W. L. Moran, OrNS 28 (1959) 136.

$42 \mathrm{H}$. Edhem Memorial I I $42 \mathrm{ff}$.

${ }^{43} \mathrm{H}_{1}$ A III $7 \mathrm{ff}$. (in B fast völlig verloren). 
gewöhnlich ist aber der Vorwurf, keiner der Nachkommen jener Könige hätte den Verstorbenen die notwendigen Opfer gebracht, nur sie, die doch gar nicht zum Königshaus gehörte. Dies läßt sich nur erklären als Versuch, der Thronfolge Nabonids eine zusätzliche Rechtfertigung zu verschaffen: Seine Familie nahm die Pflichten wahr, die eigentlich den direkten Nachkommen des Königshauses zugekommen wären. Sie konnte daraus zu einem gewissen Grade ihr Recht auf die Nachfolge ableiten. So verstanden werden will wohl auch die Bemerkung der Mutter, daß ihr die Könige seit Nabupolassar ,,wie einer leiblichen Tochter" das Haupt erhöhten ${ }^{44}$. Es ist müßig, darüber zu spekulieren, welche Stellung am Hofe sie wirklich hatte. In diesem Punkte sind ihre Angaben merkwürdig allgemein. Es gelang ihr jedenfalls, ihren Sohn in die Nähe des Königs zu bringen ${ }^{45}$, und dieser wirkte dann wieder in ihrem Sinne. Dies alles und auch der Totenkult, der ja nur in der Hauptstadt begangen werden konnte ${ }^{46}$, macht es zur Gewißheit, daß sie sich zumindest zeitweise am Hofe in Babylon aufhielt, wo allein sie auch Einfluß nehmen konnte.

Adad-guppī erwähnt ihren Gatten mit keinem Wort und sagt auch nichts über ihre eigene Abstammung ${ }^{47}$. Das läßt sich vielleicht einfach daraus erklären, daß der Gatte im Leben der Mutter Nabonids keine besondere Rolle spielte, sie ihm nichts Erwähnenswertes verdankte, ja, daß er vielleicht schon früh gestorben war. Auch Nabonid nennt ihn in $\mathrm{H}_{2} \mathrm{~A} / \mathrm{B}$ nicht, gibt aber in anderen Inschriften seinen Namen als Nabû-balātsu-iqbi an, zusammen mit den Titeln $r u b \hat{u}$ „Fürst" oder šakanakku ,Statthalter"48. Das sagt uns allerdings wenig. B. Landsberger hat vermutet, daß er das Oberhaupt eines in Babylonien beheimateten Aramäerstammes war und den Absender der Briefe ABL $7 \mathrm{I} 6-7 \mathrm{I} 8$ gleichen Namens für seine Identifizierung in Erwägung gezogen $^{49}$. Die Briefe dürften während und kurz nach dem Bruderkampf Assurbanipal-Šamaššumukin $(652-648$ v. Chr.) geschrieben sein,

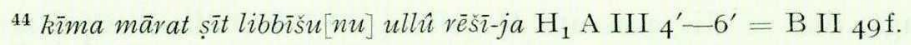

${ }^{45} \mathrm{H}_{1}$ A II $45-49=$ B III x-3'.

46 Es ist zwar nicht beweisbar, daß sich die Gräber der bab. Könige in Babylon befanden, da sie bisher nicht ausgegraben sind, doch ist es sehr wahrscheinlich. Das von E. Unger, Babylon (I93I) 5Iff.; 237, 4f. und RlA I 368 a nach der Stadtbeschreibung in der Neustadt gesuchte „Mausoleum“ der Könige gab es dort sicher nicht, vgl. B. Landsberger, ZA 4I (I932) 297 mit Anm. I.

47 Auf diese Eigentümlichkeit hat bereits Gadd, S. $90^{5}$ hingewiesen.

48 rubû: VAB 4, 2I 8 I 6; 230 I I 3; 234 I 30; 262 I I6; 294: I0, 3; I I, 6; I2, 3; RA 22, 6I I 32; UM I 5, 80 I I2; RA I I, I Io, 23; OEC I pl. 23, 20 u. Dupl. ; Sumer I3, I9I I 35. - Šakanakhu: VAB 4,252 I 9.

${ }^{49}$ H. Edhem Memorial I I 50 f.; s. aber H. Lewy, ArOr. I7/2 (I949) $36^{36}$. 
enthalten jedoch nichts, was für die Stellung ihres Verfassers zum König bzw. zu seinen babylonischen Untertanen besonders aufschlußreich wäre ${ }^{50}$.

Abgesehen davon, daß bei der relativen Häufigkeit des Namens Nabû-balātsu-iqbi die Hypothese von der Identität der beiden Personen erst noch weiterer Stützen bedürfte - und auch Landsberger hat ja diese Identität keineswegs als sicher hingestellt —, macht auch die Frage der Chronologie Nabonids dabei gewisse Schwierigkeiten. Landsberger räumt ein, daß die Königsmutter ,,in sehr jungem Alter einem älteren Manne verheiratet worden sein müßte". Adad-guppī ist, wenn man einmal die chronologischen Schwierigkeiten, die sich durch ihre Angaben ergeben ${ }^{51}$, hintan stellt, nach Angaben der Stelen $\mathrm{H}_{1} \mathrm{~A} / \mathrm{B}$ und der Nabonid-Kyros-Chronik am 5. Nisan des 9. Jahres Nabonids (= $7 . \mathrm{IV} .547 \mathrm{v}$. Chr.) im gesegneten Alter von I04 Jahren gestorben, wurde also um 650 v. Chr. geboren. Falls man nicht annehmen will, daß Nabonid im höchsten Greisenalter zur Regierung kam ${ }^{52}$, muß man seine Geburt etwa um 6 Io v. Chr. ansetzen, als seine Mutter schon ca. 40 Jahre alt war. Sollte die Hypothese von der Identität des Nabûbalātsu-iqbi mit dem Verfasser der Briefe an Aššur-bān-apli zu Recht bestehen, so müßte er die Briefe entweder in noch recht jugendlichem Alter geschrieben haben oder noch recht betagt (6o-70 Jahre) Vater seines einzigen Sohnes (s. $\mathrm{H}_{1}$ B I 40. II I3; $\mathrm{H}_{2}$ A/B I 8) geworden sein. Eine Entscheidung über Herkunft und Person des Vaters wird sich also vorläufig nicht herbeiführen lassen.

Die Zeit der Geburt Nabonids läßt sich auch noch von einer anderen Seite her auf die Jahre um 6 Io v. Chr. eingrenzen. Adad-guppī erwähnt, daß sie ihn ,,vor Nebukadnezar, dem Sohne des Nabûpolassar und (vor) Neriglissar, König von Babylonien, stehen ließ“" ( $\mathrm{H}_{1}$ B II 45 f.), also nicht vor Nabupolassar, wohl aber seinen beiden Nachfolgern. Das ist selbstverständlich, wenn der Knabe zunächst das nötige Alter erreichen mußte, um am Hofe Dienst tun zu können. Es ist aber auch nicht gesagt, daß er die gesamte Regierungszeit Nebukadnezars an

50 Daß sie von einem Babylonier stammen, verrät die Sprache. Eine gewisse Vertrautheit mit der Literatur läßt ABL 716 Rs. 25 vermuten, wo BMS I I, I f. $=\mathrm{AGH} 72 \mathrm{~b}$ If. zitiert ist (vgl. A. L. Oppenheim, JAOS 64 (I944) 194 b). Außerdem zeigt der Brief nur eine bedingungslose Unterwürfigkeit des Absenders, vgl. Z. I6f.: йmu agâ appā ana mĩtütu alabbin ,heute demütige ich mich bis zum Tode".

51 Vgl. R. Borger, WZKM 55 (I959) $62-76$.

52 Dennoch war er bereits ein Mann von ca. 55 Jahren, als er 555 zur Regierung kam, s. u. Anm. $5^{8}$. 
dessen Hofe verbrachte, ja es ist sogar unwahrscheinlich, daß dies der Fall war. Eine Rechtsurkunde aus dem 8 . Jahre Nebukadnezars nennt einen Nabîu-na'id ša eli äli, ,N. der Stadtvogt" ${ }^{53}$, doch muß dies ein Sohn Nebukadnezars gewesen sein, da ein Duplikat dafür mār lúšarri bietet $^{54}$. Nabonid dürfte damals erst ein Alter von ca. I4 Jahren erreicht haben. Anders ist die Situation im Jahre $585 \mathrm{v}$. Chr., als nach einem Bericht Herodots ${ }^{55}$ Friedensverhandlungen zwischen Lydern und Medern stattfanden, an denen auch ,Labynetos der Babylonier“ teilnahm ${ }^{56}$. Auch hier ist die Möglichkeit nicht auszuschließen, daß wieder der gleiche Königssohn gemeint ist. Man sollte aber erwarten, daß sein prinzlicher Rang herausgehoben wäre und so besteht eine gewisse Wahrscheinlichkeit, daß der spätere König Nabonid hier seine erste diplomatische Mission antrat, also etwa in seinem 25. Lebensjahre ${ }^{57}$.

Noch etwa dreißig Jahre sollten vergehen, bis Nabonid zur Herrschaft kam58, ein Ereignis, das er offenbar selbst nicht erwartet hatte.

53 N. Strassmaier, Nbk. 70, 9 (zu AHw. 39 s. v. ălum I c).

54 S. 76-II-I7, 734, vgl. auch R. P. Dougherty, YOR I5 (I929) 29-33. Auf diesen Sachverhalt hat H. Lewy, ArOr. I $7 / 2,46^{89}$ hingewiesen und auch die Umstellung des Determinativs als Eigenheit des Textes erklärt.

${ }^{55}$ Herodot I 74. Zur Diskussion dieser Stelle s. R. P. Dougherty, a. a. O. 33-42; S. Smith, BHT 43; W. Baumgartner, ArOr. I8/I-2 (I950) $95^{126}$. Allgemein zum Friedensschlußs. J. Lewy, MVAeG 29/2 (I925) I4ff.

56 Labynetos wohl dissimilatorisch aus *Nabynetos, s. J. Lewy, a. a. O. $17^{1}$; W. Baumgartner, a. a. O. $95^{124}$. Nichts zwingt uns anzunehmen, daß hier Herodot den Namen des letzten babylonischen Königs versehentlich statt Nebukadnezar einsetzte (J. Lewy, a. a. O. I6f.). Allerdings ist Herodot über die Thronfolge in Babylon (bei ihm Assyrien) nur mangelhaft unterrichtet, da er Nabonid als Sohn eines ersten Nabonid und der Nitokris bezeichnet (I I 88).

57 Natürlich ist diese Identifikation des genannten Labynetos mit dem späteren König Nabonid nicht zwingend, da es sich bei der Häufigkeit des Namens Nabû-na'id in neubabylonischer Zeit genausogut um einen anderen Würdenträger des Hofes handeln kann.

${ }^{58} \mathrm{H}$. Lewy wendet sich in der oben (Anm. 54) zitierten Anmerkung ihres interessanten Aufsatzes ,,The Babylonian Background of the Kay Kâus Legend" gegen die Annahme, daß Nabonid erst im 6. Jahrzehnt seines Lebens zur Herrschaft berufen wurde. Ihr Einwand, der Greis von nahezu ıoo Jahren hätte kaum noch eine Revolte in Karmanien anzetteln und damit eine Gefahr für Kyros bilden können, ist auf den ersten Blick scheinbar berechtigt. Aber es ist keinesfalls sicher, daß solch eine Revolte überhaupt stattfand. Abydenos berichtet nur, daß Kyros Nabonid mit der Satrapie Karmanien betraute (F. Jacoby, Die Fragmente der griechischen Historiker III C (I958) 408f.), während Berossos allein davon weiß, daß Kyros , ihm in Karmanien einen Wohnsitz gab, ihn aus Babylonien wegschickte. Nabonid 
Leider verhilft uns die Bemerkung, ,die Königsherrschaft lag nicht in meinem Sinn", mit der die Stele über dies Ereignis hinweggeht, nicht weiter zu einem Verständnis der Vorgänge bei der Thronbesteigung Nabonids. Es wird dadurch aber die Darstellung der Hille-Stele bestätigt, daß ihm das Königtum angetragen wurde ${ }^{59}$. Er war also kein Usurpator. Selbst wenn man der offiziellen Darstellung nicht trauen will, so kann man doch aus dem Schweigen des Strophengedichts über die Thronbesteigung eine Bestätigung für ihre Richtigkeit entnehmen. Sicher hätte man sich eine so günstige Gelegenheit zur Schmähung des Königs, wie es eine unrechtmäßige Machtergreifung wäre, nicht entgehen lassen. Nabonid leitet seine Herrschaft nicht von Erbansprüichen auf den Thron her ${ }^{60}$, sondern allein vom

aber, nachdem er die übrige Zeit in jenem Lande zugebracht hatte, verschied (dort)" (F. Jacoby, ebd. 394). Es ist also höchst zweifelhaft, ob der König nach seinem Sturz noch irgendein Amt bekleidete. Die Zweifel an seinem hohen Alter zu dieser Zeit sind angesichts der jetzt vorliegenden Angaben nicht mehr berechtigt, nur wird man mit ca. 7o Jahren rechnen können. Wenn Adad-guppī erwähnt, sie habe vier Generationen heranwachsen sehen ( $\mathrm{H}_{1}$ B II 33 f.), so kann man das kaum als literarischen Topos erklären (auch die Inschrift Nērab Nr. 2 (M. Lidzbarski, Handbuch der Nordsemitischen Epigraphik S. 445) Z. 5 nennt 4 Generationen, die der Priester erlebte), sondern man muß die Realität dahinter sehen, daß Nabonid bereits in der Mitte seiner Regierung Urgroßvater war. Belsazar war also auch schon ein älterer Mann, als ihm die Verwaltung des Reiches übertragen wurde. Das harmoniert schließlich mit den oben gemachten Altersangaben, zumal eine Geburt um 590 v. Chr. wegen des Alters der Mutter (65 Jahre!) schlechterdings unmöglich ist. Man darf in diesem Zusammenhang vielleicht die Frage aufwerfen, ob hinter der Wahl eines bereits alten Mannes zum König eine Absicht steht, nämlich die, eine Übergangslösung zu finden, bis sich die Parteienkämpfe in Babylonien beruhigt hätten. Um so größer mag die Erbitterung gewesen sein, als dieser greise Herrscher doch noch eine erstaunliche Tatkraft bewies und ein eigenes politisches und religiöses Konzept zu verwirklichen begann. Es kann sich aber auch nur um eine Reaktion handeln auf das unheilvolle Regiment, das der jugendliche Labaši-Marduk führte. Da die Quellen über die Hintergründe der Wahl Nabonids schweigen, lassen sich nur Vermutungen àußern.

$59 \mathrm{Nbn}, \mathrm{Nr} .8$ (= $\left.\mathrm{VAB}_{4}, 276\right) \mathrm{V} \mathrm{I}^{\prime} \mathrm{ff}$.

${ }^{60}$ Das geht aus der zweimal gebrauchten Wendung šarrūtu ina libbri-ja lāa tabšâ (s. o. S. 227) klar hervor und wird sogar von Abydenos bestätigt (F. Jacoby, a. a. O. 408). Dafür spricht ferner die Deutung des Traumes mit der Erscheinung Nebukadnezars (VAB 4,278 ; Dreams S. 250), die von A.L. Oppenheim vorgeschlagen wurde, nämlich auf diese bisher einzigartige Weise die Legitimation des großen Vorgängers ' $z u$ bekommen, als dessen $\mathrm{Ab}$ gesandter Nabonid sich fühlte (vgl. Dreams S. 203f.). Mit Gadd (a.a. O. S. 66) ist auch auf das mār lā mammanim ,,Sohn eines Niemand“ Nabupolassars hinzuweisen. 
Willen der Götter, die durch ihr Gebet Sîn dazu bestimmen, ihn zu berufen $^{61}$.

Die direkte Fortsetzung der Zeilen I $\rightarrow 7$ a ist mit der Erzählung vom Traum und dem Befehl zum Tempelbau gegeben, nur ist der Abschnitt jetzt nicht mehr in der 2. Pers. Sing. stilisiert, sondern im Anschluß an dSin ibbânni in der 3. Pers. Sing. Auffällig ist, daß - bei der Fiktion, daß der Gott selbst das Wort führt - vom ,Tempel des Sin" gesprochen wird, nicht, wie zu erwarten, von ,meinem Tempel“. Zur Erklärung muß der Text herangezogen werden, in dem vom Traum des Königs ebenfalls berichtet wird, Nbn. Nr. I (=VAB 4 , 2I8) I I $8 \mathrm{ff} .{ }^{62}$. Dort ist es Marduk, der dem König den Auftrag zum Tempelbau gibt, und es ist vollauf berechtigt, daß in diesem Zusammenhang davon gesprochen wird, daß ,,Sîn, der große Herr, darin (im Tempel) seinen Wohnsitz aufschlagen soll“. Man muß also annehmen, daß der vorliegende Text eine schlechte Adaption der Vorlage Nbn. Nr. I darstellt, ein neues Argument für die bereits von W. L. Moran konstatierte Abhängigkeit der Texte voneinander. Die Verheißung, daß alle Länder Nabonid zufallen sollen, findet sich dagegen in Nbn. Nr. I nicht und ist folglich auch hier exakter, nämlich in der I. Pers. Sing. formuliert.

Will man nicht annehmen, daß ein Bruch im Gedankengang vorliegt, so kann man den folgenden Bericht über die Widersetzlichkeit der Babylonier nur als logische Folgerung aus dem vorhergegangenen Auftrag des Sîn und seiner praktischen Durchführung, dem Tempelbau in Harrān, verstehen. Daß dies zutrifft, lehrt das Strophengedicht ${ }^{63}$, das von Kol. I I $_{5}$ bis II I5 die Reaktion der Babylonier auf den Tempelbau Nabonids und die Aufstellung eines fremden Götterbildes anschaulich vor Augen führt. Der neue Text gibt nun eine klare Bestätigung der Vermutung, die schon bald nach Bekanntwerden des

${ }^{61}$ Das ist insofern auffällig, als hier die ,Berufung“" Nabonids durch Sîn besonders hervorgehoben wird. Sie erfolgt ebenfalls durch Sîn allein in der Inschrift UM I 5, 80, 8, durch Sîn und Samaš in VAB 4, 230 I 5 (vgl. 228, 43). Ungleich häufiger ist es Marduk, dem die Berufung zugeschrieben wird: VAB 4, 234 I 2. I3ff.; 252 I 6 (neben Nabû); 262 I I7; 276 V 8; 294 : 10, 2 (neben Nabû); CT 36, 21, 25 u. Dupl.; Sumer 13, I90 I 2. Für das Verhältnis Nabonids zu Marduk bzw. Sîn besagt das aber nicht viel. In den Texten aus Babylonien wird traditionsgemäß Marduk die erste Stelle zuerkannt, im fernen Harrān aber kann der König seiner Vorliebe für den Mondgott gebührend Ausdruck verleihen.

62 Vgl. A. L. Oppenheim, Dreams $202 \mathrm{f}$; 250.

${ }^{63}$ Edition von S. Smith, BHT 27-97; Pl. V-X; s. B. Landsberger Th. Bauer, ZA 37 (1927) 88-98; A. L. Oppenheim, ANET 3I2-315. 
Strophengedichtes geäußert wurde ${ }^{64}$ : Die Reaktion ging von den zentralbabylonischen Städten Babylon, Borsippa, Nippur, Ur, Uruk und Larsa aus. Diese fühlten sich offenbar durch die neue Entwicklung benachteiligt, obgleich ihnen doch von Nabonid in herkömmlicher Weise - wenn nicht darüber hinaus - Tempel gebaut und Opfer gestiftet wurden ${ }^{65}$. Hier wirkt sich allerdings für unsere Kenntnis der Dinge der Umstand erschwerend aus, daß wir die Bauten Nabonids nach den Inschriften nicht exakt datieren können ${ }^{66}$. Es wäre ja möglich, daß die rege Bautätigkeit an manchen Orten erst eine Folge der Vorhaltungen der Babylonier und ein Eingehen auf deren Wünsche war. Auch die Wortführer der babylonischen Partei, die Priester, werden

64 S. Smith, BHT 32; s. B. Landsberger, ZA 37 (1927) 96; H. de Genouillac, RA 22 (I925) $75 \mathrm{ff}$.

65 An Bauten des Königs sind uns bekannt:

I. Babylon: Emašdaria der Ištar H. Ehelolf, WVDOG 47 (I926) I36f. (= S. Smith, RA 22 (I925) $57-66$ ).

Stadtmauer Imgur-Enlil UM r 5, 80.

2. Sippar: Ebarra des Samaš VAB 4, 224 II 47-III 2 I u. Dupl.; 230 I I4 bis II $35 ; 242$ I IIff.; $248,24 \mathrm{ff}$; $254 \mathrm{ff}$; 262 , I $7 \mathrm{ff}$; OEC I pl. $23-28$; CT 34, 27 I 42-II 26; CT 36, 22 I 34-37 u. Dupl.

Ekur des Bunene VAB 4, 232 I $30-33$.

3. Sippar-Anunit: E’ulmaš der Anunit VAB 4, 228, 22-50; 248, $24 \mathrm{ff}$. ; CT 34, 34 III 26-77.

4. Larsa: Ebarra des Šamaš VAB 4, 234 I 3I ff. ; 242 I 43 ff.; CT 34, 26 I I-39.

5. Akkade: E’ulmaš der Ištar $\mathrm{VAB}_{4}, 246$ II 29-III 65; CT 34, 30 II 28 bis III 24 .

6. Ur: Egišnugal mit Ziqqurrat $\operatorname{VAB} 4,250-252 ; 296 \mathrm{Nr}$. I3. I4; R. C. Thompson, CLBT (I927) AB 239.

Egipar des Sîn VAB 4, 296 Nr. I 5 UET I, I 87; YOS I, 45 I $39 \mathrm{ff.}$

7. Harrān: Ehulhul des Sîn VAB 4, 2 I 8 I 8 ff.; 284 X I2ff.; $\mathrm{H}_{2}$ A/B.

8. Ubase mit Kapelle der Nanâ CT 36, 22 II 5-7 u. Dupl.

9. Kutha: Stadtmauer Ugalama'uru CT 36, 22 II I u. Dupl.

10. Kiš: Stadtmauer Melamkurkuradulla CT 36, 22 II 2 u. Dupl.

Bit Akitu des Ninurta CT 36, 22 II 3 f. u. Dupl.

II. Marad: E'igikalama CT 36, 22 II $26 \mathrm{ff}$. u. Dupl.

12. Dūru (Tell el-Laḥm) : E’amaškuga der Ningal Sumer I3 (I957) I9I I 36 ff. ${ }_{66}$ Nur vom Ebarra in Larsa wird berichtet, daß seine Restaurierung im Io. Jahre Nabonids in Angriff genommen wurde (VAB 4, 236 I 54; 244 I 65). Die Restaurierungsarbeiten in Ur lassen sich zeitlich ungefähr festlegen, da sie im Zusammenhang mit der Einsetzung der Tochter Nabonids als EnPriesterin gestanden haben. Die Investitur erfolgte im 2. oder 3. Regierungsjahr des Königs (das Omen YOS I, 45 I $8 \mathrm{ff}$, bezieht sich auf den 26. September 554, vgl. H. Lewy, ArOr. I $7 / 2$ (I949) $5 \mathrm{I}^{105}$ ), die Bauten gehören also an den Anfang der Regierung Nabonids. Weitere Anhaltspunkte gibt es m. W. nicht. 
genannt, doch scheint es mir durchaus zweifelhaft zu sein, ob diese eine regelrechte Revolte entfesselten, wie dies Gadd vorauszusetzen scheint ${ }^{67}$. Jedenfalls wird davon nirgends etwas berichtet, vielmehr gibt Nabonid an, daß sie ,einander wie Hunde fraßen“, d. h. wohl, daß die Gegenpartei nicht einheitlich war, sondern die Priesterschaften verschiedener Tempel jeweils ihre eigenen Interessen verfochten. Dem König war es wahrscheinlich möglich, die Parteien gegeneinander auszuspielen und dadurch ihren Einfluß erheblich zu verringern. Hätte eine Revolte stattgefunden, so wäre es dem König wohl kaum eingefallen, dem Kronprinzen allein die Herrschaft zu überlassen und sich Io Jahre lang außer Landes zu begeben, da dies das sichere Ende seiner Regierung bedeutet hätte. Die Entwicklung dürfte allerdings so gegangen sein, daß die Priester in Babylon, wohl am meisten von Nabonid benachteiligt, sich von außen Hilfe suchten, da sie im Inneren keine geschlossene Front aufbauen konnten, und die Perser ins Land riefen, denen es schließlich auch fast kampflos in die Hand fiel. Kyros stattete seinen Dank dadurch $\mathrm{ab}$, daß er die Heiligtümer Babylons schonte und die Stadt in jeder Hinsicht bevorzugte ${ }^{68}$.

\section{Aufenthalt in Arabien}

Der Bericht der Stelen $\mathrm{H}_{2} \mathrm{~A} / \mathrm{B}$ über den Aufenthalt in Tēmā bietet unerwartete Details, läßt aber nach wie vor keine sichere Antwort auf die Kernfrage geben: Was veranlaßte Nabonid, sich Io Jahre lang fern von seiner Residenz in der arabischen Wüste aufzuhalten?

Der Zeitpunkt, zu dem der König sein Land verließ, wird in den Stelen nicht angegeben. Er läßt sich aber aus der Nabonid-KyrosChronik gewinnen, wo es für die Jahre 7 und 9-II heißt: šarru ina

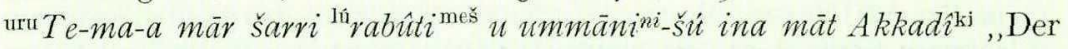
König (befand sich) in Tēmā, der Kronprinz, die Großen und sein Heer (befanden sich) in Akkade"“69. Der Text des 6. Jahres ist am

67 AnSt. 8 (1958) 74. Auch H. Lewy (a. a. O. 53 ff.) rechnet mit einer Rebellion zu Beginn der Regierung Nabonids, doch kann man humé in VAB 4, 284 IX 32 und BHT I I I 7 nicht als ,,Rebellen“ erklären. Es ist vielmehr die Bezeichnung für Kilikien (assyrisch Qū’e) in neubabylonischer Zeit, vgl. W. F. Albright, BASOR I2O (1950) 23; D. J. Wiseman, CCK S. 87; CAD H 234 a; Ph. Houwink ten Cate, The Luwian Population Groups of Lycia ... (196I) I7.

68 Strophengedicht Kol. VI; VAB 3, 2 ff.

${ }^{69}$ BHT II ff. Vgl. C. J. Gadd, AnSt. 8, 79 und die Angabe des Strophengedichtes (II I8ff.) ,.... er übergab das Feldlager dem Erbsohne, seinem Erstgeborenen, die Truppen von allüberall unterstellte er dessen Befehl. Er 
Anfang nicht erhalten, auch von den vorhergehenden Jahren ist er nur bruchstückhaft überliefert. Es ist aber sehr wahrscheinlich, daß der Auszug im 6. Jahre stattfand. Für die Dauer des Aufenthaltes war man bisher auf Vermutungen angewiesen, man schätzte 7 oder 8 Jahre dafür $e^{\text {ein }}{ }^{70}$. Der Text der Stele spricht nun eindeutig von Io Jahren, die der Aufenthalt in der Wüste dauerte. Falls die Zeit des Auszuges richtig bestimmt ist, bedeutet das, daß die Rückkehr nur knapp ein Jahr vor der Einnahme Babylons durch Kyros erfolgte. Als Datum darf wohl der I7. Tašrit des I6. Regierungsjahres (= 25. X. 540) angesetzt werden, so daß das Neujahrsfest des Jahres 539, von dem die Chronik ausführlich berichtet ${ }^{71}$, das erste war, das nach vielen Jahren wieder in Babylon gefeiert wurde. Hier kann an den Bericht des Xenophon erinnert werden, der davon spricht, daß Kyros, nachdem er sich die Phryger und Kappadokier unterworfen hatte, auch die Araber untertänig machte, noch bevor er sich gegen Babylon wendete ${ }^{72}$. Diese Nachricht wird durch Berossos und den Kyros-Zylinder gestützt ${ }^{73}$, wonach auch die ,Zeltbewohner des Amurru-Landes" ihren Tribut brachten. Die Vermutung liegt nahe, daß der Abzug Nabonids aus Tēmā, von ihm als Erfüllung der von Sîn bestimmten Zeit gedeutet, nicht ganz freiwillig erfolgte, sondern bereits unter dem Druck der neuen Weltmacht des Kyros.

legte (die Herrschaftsembleme) aus der Hand, übergab jenem das Königtum, er selbst aber machte sich auf einen weiten Weg. Die Streitkräfte von Akkade stehen an seiner Seite, nach der Stadt Tēmā, mitten im Amoriterlande, beabsichtigt er zu ziehen."

70 Die Sieben-Zahl ergab sich im Anschluß an Daniel 4, I3. 22. 29, wonach Nebukadnezar 7 Jahre unter den Tieren der Wüste zugebracht haben soll, eine Episode, die vom Wüstenaufenthalt Nabonids auf den größten neubabylonischen König übertragen wurde. Die bisher meist akzeptierte Periode von 8 Jahren leitete ihre Berechtigung daher ab, daß der Beginn der Aktion in Arabien wahrscheinlich im 6. Jahre lag, da unter diesem Datum bereits eine Rechtssache durch den Kronprinzen abgewickelt wurde und auch die Chronik diese Ansetzung zu befürworten scheint (s. R. P. Dougherty, Nabonidus and Belshazzar, YOR I5 (1929) I25ff.). Das Ende dieser Periode ließ sich nur daraus gewinnen, daß man aus dem Schweigen aller Texte über irgendwelche Aktivität Belsazars nach dem I 4. Jahre Nabonids schloß, der König sei dann wieder im Lande gewesen (s. R. P. Dougherty, a. a. O. 85. I61. 182). Aber schon S. Smith vermutete, daß die Rückkehr Nabonids aus Tēmā erst in die Jahre $540-539$ fiel (BHT ro2f.).

71 BHT II 2 .

72 Xenophon, Cyrupaedia 7, 4, I6; vgl. R. P. Dougherty, a.a. O. I63; BHT Io2f.

${ }^{73}$ Fl. Josephus, Contra Apionem I 20 (F. Jacoby, Die Fragmente der griech. Historiker III C 393, I 5 ff.), vgl. R. P. Dougherty, a. a. O. I62; VAB 3, 6, 29. 
Das mußte aber bedeuten, daß ein Plan für eine politische Allianz, falls ihn Nabonid mit seinem Zug nach Tēmā und in die anderen Oasen der arabischen. Halbinsel verfolgte, gescheitert war. Vorausgesetzt allerdings, daß es einen solchen Plan überhaupt gab. Leider gibt auch der neue Text keine klare Antwort auf die Frage nach dem Grund der Unternehmung ${ }^{74}$, doch darf wohl vorausgesetzt werden, daß der König nur aus einem zwingenden Grund sein Stammland verlie $\beta$, zumal ihm das Wachsen der Gefahr im Osten kaum verborgen geblieben sein kann.

Nabonid selbst gibt als Grund für seinen Auszug nach Tēmā die Uneinigkeit der Babylonier und die darauf folgende Strafe der Götter (oder Sîns?), Krankheit und Hunger an $\left(\mathrm{H}_{2} \mathrm{~A} / \mathrm{B}\right.$ I $20 \mathrm{ff}$.). Wir wissen nicht, wann diese Seuche im Lande grassierte. Im Allgemeinen - und das ist auch gegenüber den Anschuldigungen des Strophengedichtes festzuhalten - zeichnete sich die Wirtschaft der Zeit Nabonids durch außerordentliche Prosperität aus, die meisten Rechts- und Wirtschaftsurkunden des neubabylonischen Reiches sind uns aus seiner Regierungszeit überliefert ${ }^{75}$. Nur ein einziges Mal wird eine Hungersnot erwähnt, die für eine Witwe zum Anlaß wird, ihre beiden Söhne dem Tempel Eanna in Uruk zu übergeben. Diese Urkunde stammt aus dem Ir. Jahre des Königs, in dem er sich sicher in Arabien befand ${ }^{76}$. Trotzdem dürfen wir wohl annehmen, daß hinter den Worten des Königs eine Realität steht, zumal die spätere Tradition dieses Motiv aufgegriffen hat, wenn auch dahin umgedeutet, daß der König selbst von einer Krankheit - sei es Wahnsinn oder sei es Lepra - betroffen wurde und deshalb sein Land verließ77. Es kann jedoch als ausgeschlossen gelten, daß

${ }^{74}$ Verschiedene Vorschläge werden diskutiert bei R. P. Dougherty, a. a. O. I38ff.; vgl. ferner B. Landsberger-Th. Bauer, ZA 37 (r927) $96 \mathrm{ff}$. (Versuch einer Koalition mit aram. Stämmen der Wüste); J. Lewy, HUCA I9 (I945/6) $436 \mathrm{ff}$. (ungestörte Verehrung des Mondgottes); C. J. Gadd, AnSt. 8, 88 (Flucht vor einer Rebellion in Babylonien).

75 H. Lewy, ArOr. I 7/2 (1949) 58 mit Anm. I33.

${ }_{76} \operatorname{YOS} 6$, I 54, 6f.: su-un-qa ina ma-a-ta šá-kin ,Hunger herrschte im Lande", vgl. A. L. Oppenheim, Iraq 17 (1955) 72.

77 Die späteren Ausdeutungen des Schicksals des Königs können hier nicht diskutiert werden. Schon nach Bekanntwerden des Strophengedichtes war es klar, daß die Erzählungen in Kap. 2-4 (oder 5) des Danielbuches auf Volkserzählungen zurückgehen, die sich der Gestalt des letzten babylonischen Königs angenommen hatten (vgl. W. von Soden, ZAW 53 (I935) 84ff.; H. Lewy, ArOr. I7/2 (I949) 33; dagegen A. Bentzen, Daniel, Handbuch z. AT I9 $^{2}$ (1952) 45). Daß sie dort Nebukadnezar zugeschrieben wurden, war nicht weiter verwunderlich, da ja Herodot schon keine exakte Kenntnis der historischen Vorgänge des letzten Jahrhunderts babylonischer Geschichte mehr besaß (vgl. W. Baumgartner, ArOr. I8/I-2 (I950) 83ff.). Diese Un- 
Hungersnot und Krankheit allein den Aufbruch des Königs bedingten. Vor allem wäre es dann ja völlig unverständlich, warum er ganz Arabien durchzieht und dabei bis Jatrib (Medina) vordringt ${ }^{78}$, wie es der neue Text berichtet. Ein kurzer Aufenthalt in Tēmā hätte ja vollkommen genügt. Wir müssen also nach einem anderen Grund für den Wüstenzug Ausschau halten.

Der Abschnitt I 27b-II to ist sehr klar gegliedert. Sin hat den Göttern Šamaš, Ištar, Adad und Nergal die Sorge für das Wohlergehen des Königs aufgetragen, und in etwas veränderter Reihenfolge wird dann der Beitrag jeder Gottheit zur Ausführung des göttlichen Befehls geschildert.

Zunächst das Wirken des Wettergottes Adad (I 3I-38). Der Passus bietet eine Schwierigkeit, auf die bereits Gadd hingewiesen hat ${ }^{79}$; da zuerst von zweimaliger Ernte ina šatti šâšs $u^{80}$,,in dem eben genannten Jahre" gesprochen wird, ohne daß sich aus dem Text ersehen läßt, welches Jahr gemeint ist. Dann heißt es jedoch, daß ina kal šanäti annâti , in all diesen Jahren" auch in den Sommermonaten Regen fiel, so daß dem König reichlich Abgaben gebracht werden konnten. Diese Diskrepanz läßt sich nicht klären ${ }^{81}$. Man könnte vermuten, daß es sich bei ,allen diesen Jahren" um die Jahre des Aufenthaltes in Tēmā handeln soll und die Hilfe, die Adad dem König gewährte, darin bestand, daß auch in der Wüste in den betreffenden Jahren Regen fiel. Dem steht entgegen, daß sich das Suffix von išaqqī-šunūti $(Z .37)$ nur

kenntnis kann aber nicht allgemein verbreitet gewesen sein, da durch ein aramäisches Fragment eines ,,Gebetes des Nabonid“, das in den Höhlen am Toten Meer zum Vorschein kam, eine Tradition greifbar wird, die noch von Nabonid selbst spricht. VgI. vorläufig J.-F. Milik, RB 63 (I956) 407-4I5; R. Meyer, ThLZ 1960, 83I-834; Dslb., Das Gebet des Nabonid. Sitzungsberichte d. Sächs. Akad. d. Wissenschaften zu Leipzig, phil.-hist. Kl. ro $7 / 3$ (I962).

${ }^{78} \mathrm{Zu}$ den im Text genannten Oasen und ihren antiken und modernen Bezeugungen vgl. ausführlich C. J. Gadd, AnSt. 8, 80-86.

79 Gadd, a. a. O. S. 67.

${ }^{80} \mathrm{Zu}$ erwarten wäre natürlich šâši, vgl. GAG §4זі. Zur Ersetzung der femininen Formen der Pronomina durch die maskulinen in den Stelen vgl. schon B. Landsberger, H. Edhem Memorial I $133^{3}$. Man darf wohl mit einem weitgehenden Verlust der kurzen Endvokale überhaupt rechnen, s. GAG § I 3 c ; oben S. 23 I zu II 3 I.

81 Nur die Vermutung sei hier gewagt, daß ina šatti šâsu noch zum vorhergehenden Satz zu ziehen wäre: ,Auf Befehl des Sîn-Nannar hatten Śamaš, Ištar, Adad und Nergal auf den Schutz meines Wohlergehens und Lebens in diesem Jahre acht." Auch dann sollte aber von mehreren Jahren die Rede sein. Wahrscheinlich sind beide Texte nicht ganz korrekt. 
auf die niše Akkadî u Hatti (Z. 32) beziehen kann. Es muß also Babylonien und Syrien gemeint sein.

Daß die Erntezeiten auf Nisān und Tašrit festgesetzt sind, widerspricht dem Befund der Wirtschaftsurkunden nicht: Ernte der Gerste usw. etwa im I. Monat, Ablieferung im 2.-3. Monat; Ernte der Datteln im 7. Monat ${ }^{82}$. Dennoch dürfte die Angabe nicht allzu wörtlich zu nehmen sein, sondern eine schematische Einteilung des Jahres in zwei gleiche Teile voraussetzen. Allerdings wird das Schema gleich danach wieder durchbrochen, indem die Monate III-VII als Zeit der größten Hitze bezeichnet werden. Das entspricht nur ungefähr den natürlichen Gegebenheiten, nämlich dann, wenn man den Jahresanfang möglichst früh ansetzt, so daß der 3. Monat etwa auf Mai/Anfang Juni, der 7 . auf September/Anfang Oktober fällt ${ }^{83}$. Allerdings ist es sonst meist üblich, die Monate VI und VII mit ,"Wind und Wetter" bereits zum Winter zu rechnen, obgleich es dafür offenbar keine streng verbindlichen Normen gab ${ }^{81}$. Jedenfalls sollen die Monate Simān bis Tašrit, die gewöhnlich eine Zeit der Trockenheit waren — nur der September konnte wieder etwas Regen bringen -, , in diesen Jahren "durch Regen gesegnet sein. Es ist kaum wahrscheinlich, daß diese Angabe mehr bezwekken soll, als die Kennzeichnung der Regierung Nabonids als Segenszeit ${ }^{85}$.

In diesen Zusammenhang gehört auch ein Dokument, das nun mit Sicherheit Nabonid zuzuweisen ist und das in dem uns erhaltenen Teil einen Rechenschaftsbericht über die wirtschaftliche Situation gibt: BBS Nr. $37\left(=\mathrm{H}_{3}\right)^{86}$. Die deutbaren Reste der Rückseite lauten:

82 Vgl. B. Landsberger, JNES 8 (I949) 25of.; $260 f$.

${ }^{83}$ Das trifft allerdings während der Regierungszeit Nabonids relativ selten zu.

Der I. Simān schwankt zwischen dem 20. 5. und 24. 6., der I. Tašrīt zwischen dem 19. 9. und 21. 10., s. R. A. Parker-W. H. Dubberstein, Babylonian Chronology (I956) 29.

${ }^{84}$ Dies machen die Darlegungen B. Landsbergers in dem oben genannten Artikel S. $249-253$ evident.

85 Regen als Zeichen göttlichen Segens z. B. in Segensformeln: AKA IO2, $27 \mathrm{f}$.

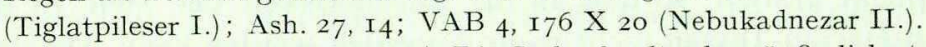

86 Ebd. Pl. XCIIIf. (= BM 90837). Die Stele ähnelt schon äuBerlich stark den neu gefundenen Texten, sie ist wie diese am Kopf mit einem Relief des Königs geschmückt (s. dazu E. Unger, AfK 2 (I924/5) 22f.). Die Inschrift ist leider bis auf wenige Zeilen getilgt. Von B. Meissner zunächst Assurbanipal (OLZ I9I8, II9-I23), später Šamaš-šum-ukīn zugeordnet (Warenpreise in Babylonien, APAW I936, phil.-hist. Kl. Nr. I, $5^{10}$ ), wurde sie von E. Unger Asarhaddon zugeschrieben (R. Borger, Ash. § 107). Schon B. Landsberger, H. Edhem Memorial I I $8^{2}$ erkannte aber die enge Verwandtschaft mit der damals bekannten Harrān-Stele $\mathrm{H}_{1} \mathrm{~A}$, die sich jetzt glänzend bestätigt hat (C. J. Gadd, AnSt. 8, 35 ${ }^{1}$ ). 
cp-še-ti-ja damqāti $\left(\mathrm{SIG}_{5}\right)^{\mathrm{meš}}$ ha-diš ip-pa-lis-ma

$a-r a-k u[\bar{u} m] e^{-m e s ̌ s} i-q \dot{i}-s \hat{a}-a n-n i$ ina a-mat d Sin

šàr ilā $\left[n i^{\mathrm{me}}\right]^{\breve{s}} \mathrm{~d} A d a d z v \cdot n n a\left(\mathrm{~S}_{\mathrm{E} G}\right) \dot{u}-[m a s ̌-] s ̌ i-r a-a m-m a$

dÉ-a ú-pat-ti-ra naq-bu-šú mešs-ru-ú

5 nu-uh-šú u hé-gál-la ina mäti-j[a] iš-ku-un

I kìr 54 (qa) utțati a-na I šiqil kaspi I kür go (qa) suluppi

[a-]na I šiqil kaspi 3o? (qa) šamaššsammi a-na I šiqil kaspi

I8 (qa) ú-le-e a-na I šiqil kas[pi] 5 ma-na šipātiłá

a-na I šiqil kaspi ištēen $n^{e n}$ ma-na x x a-na I šiqil kaspi

Io [karāa]na šikar(KAšs!.SAG) šadî šá ina qírib mäti-ja ja-a-nu I8? (qa) karāni a[-n]a I šiqil kaspi mah̄iru ina qírib māti-ja $[t u-u] h^{?}-d\left[\begin{array}{ll}u & u\end{array}\right]$ mešs-ru-ú ina māti-ja iš-ku-un

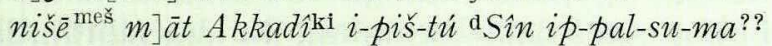
$[i p-l a-h u$ ilū $] t^{u t}-s u$ rabìtu $u^{t u ́} u \mathrm{~d}[S \hat{\imath}] n$ šàr ilāni ${ }^{\text {meš }}$

I5

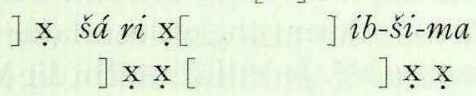

${ }^{1}$ Meine guten Taten sah er (Sîn) freundlich an, 2langes Leben schenkte er mir. Auf das Wort des Sîn, ${ }^{3}$ des Königs der Götter, hin schickte Adad Regen und ${ }^{4} \mathrm{Ea}$ öffnete seine Quelle. Reichtum, ${ }^{5}$ Fülle und Überfluß brachte er (Sîn) in meinem Lande hervor. ${ }^{6}{ }_{234}$ Sila Gerste (erhielt man) für I Sekel Silber, 270 Sila Datteln ${ }^{7}$ für I Sekel Silber $30^{\text {? Sila }}{ }^{87}$ Sesam für I Sekel Silber, I8 Sila Feinöl für I Sekel Silber, 5 Minen Wolle ${ }^{9}$ für I Sekel Silber, I Mine ? ? 88 für I Sekel Silber. ${ }^{10}$ (Vom) Wein, dem Rauschtrank des Gebirges, den es in meinem Lande nicht gibt, ${ }^{11}$ I 8? Sila Wein für I Sekel Silber (betrug) der Preis in meinem Lande. ${ }^{12}[\mathrm{Fül}] 1[\mathrm{e}$ und] Reichtum brachte er (Sîn) in meinem Lande hervor. ${ }^{13}$ [Die Leute des] Landes Akkade sahen die Tat des Sîn und ${ }^{14}$ [fürchteten] seine große [Gotth]eit. Und [Sî]n, der König der Götter ... (Von Z. 15 und I6 sind nur noch Spuren erhalten.)

Auch in diesem Text wird der Befehl des Sîn für die günstige Entwicklung im Lande verantwortlich gemacht und der Mondgott in den Mittelpunkt gestellt, so daß an der Zugehörigkeit der Stele zu den übrigen Harrān-Texten nicht mehr gezweifelt werden kann. Die Tendenz ist genau der unseres Abschnittes aus $\mathrm{H}_{2} \mathrm{~A} / \mathrm{B}$ gleich, nur daß noch genauere Preisangaben zugefügt sind. Diese sind zwar leicht tendenziös

87 Die Lesung ist nicht ganz sicher, vielleicht steht vor dem Zeichen (5 BAN) noch ein senkrechter Keil (= I PI). Nach den gebräuchlichen Wertrelationen (s. u.) ist aber 30 (qa) wahrscheinlich.

${ }^{88}$ Die Lesung der beiden Zeichen ist leider nicht zu gewinnen. Man erwartet ein Metall o. ä., allerdings ist mir keines mit dem Wertverhältnis 60: $\mathrm{I}$ aus neubabylonischer Zeit bekannt (vgl. B. Meissner, Warenpreise 3of.). 
gefärbt, d. h. möglichst günstig angegeben, halten sich aber durchaus im Rahmen dessen, was nach den Wirtschaftstexten der Zeit üblich war ${ }^{89}$. Selbst wenn man die Angaben nicht allzu wörtlich nimmt, dürfte die düstere Schilderung vom Wirtschaftsleben zur Zeit Nabonids, die das Strophengedicht (Kol. I I-I4) gibt, nicht oder nur zu einem kleinen Teil zutreffen, vor allem darin, daß der König den wirtschaftlichen Reichtum seines Landes für seine Unternehmungen - Bauten und Kriegszüge - nützte. Das bringt er in $\mathrm{H}_{2} \mathrm{~A} / \mathrm{B} \mathrm{I} 37 \mathrm{f}$. auch selbst zum Ausdruck.

Das Wirken der Ištar wird, falls die Deutung richtig ist, vor allem im Schutz der Bevölkerung und dem Friedensersuchen der feindlichen Fürsten gesehen. Die Ausdrucksweise ist dabei so allgemein, daß Schlüsse auf die historische Situation aus dem Passus nicht gezogen werden können, zumal wir über die Kriegszüge Nabonids nur sehr schlecht informiert sind. In seinen ersten Regierungsjahren zog er nach Nordsyrien, doch sind die Nachrichten darüber zu unvollständig, um eine Rekonstruktion der Aktion zuzulassen ${ }^{90}$. Von Feldzügen gegen Ägypten und Medien (bzw. Persien) erfahren wir nichts. Das Strophengedicht ( $\left.\mathrm{V}_{2}-7\right)$ bemerkt zynisch: ,,Was er nicht erobert hat, darüber schreibt er [...]. Kyros ..., die Könige aller Länder ziєh[en sein Joch]; aber er (Nabonid) schreibt auf seine Steintafel: Ich habe ihn unter meinen Fuß [gebeugt], seine Länder hat meine Hand erobert, seinen Besitz habe ich [nach meiner Residenz] gebracht". Zweifellos liegt hier eine propagandistische Übertreibung der Gegenpartei vor; bisher kennen wir keinen Text, in dem sich Nabonid entsprechender Taten rühmt. Mit einem Feldzug gegen Kyros ist jedenfalls nicht zu rechnen. Die tatsächlichen Verhältnisse dürften die gewesen sein, daß der König eine Zeit lang mit Ägypten und Persien in Kontakt stand, vielleicht auf der Basis eines - modern gesprochen - Nichtangriffspaktes. Das verschaffte ihm wohl auch die Illusion, daß ihm von Persien keine unmittelbare Gefahr drohe ${ }^{91}$. Andererseits gab es Kyros die

89 Gerste: I92 Sila für I Sekel, einmal 270 Sila Emmer für das gleiche Geld. Sesam: I $8-36$ Sila für I Sekel, also u. U. sogar billiger als die Stele wahrscheinlich angibt. - Datteln: I80-437 Sila für I Sekel, durchschnittlich I 80 Sila. - Wolle: $2 \frac{1}{2}-5$ Minen für I Sekel. Angaben nach B. Meissner, Warenpreise in Babylonien.

${ }_{90}$ BHT I Iof.; E. F. Weidner, JSOR 6 (I922) I I9 (Rs. ?). In den Harrān-Stelen werden diese Feldzüge nicht erwähnt. Da aber noch von den ,Leuten von Akkade und Hatti von der Grenze Ägyptens am oberen Meer bis zum unteren Meer" die Rede ist, wird das Gebiet noch gehalten worden sein.

${ }^{91}$ Vielleicht ist von daher die — zumindest in den ersten Regierungsjahren recht günstige Einschätzung des Kyros als ,,junger Diener (des Marduk) " in 
Gewähr, daß ihm bei seinen Eroberungszügen im westlichen Kleinasien der Babylonier nicht in die Flanke fiel.

Anders scheint die Situation bei den Arabern gewesen zu sein, denen außer der Erwähnung bei den Taten der Ištar noch der folgende Abschnitt, die Taten des Nergal, gewidmet ist. Leider ist gerade dieser wichtige Passus ziemlich zerstört, doch läßt sich mit hinreichender Sicherheit erkennen, daß zunächst ein Raubzug der Araber nach Babylonien erfolgte. Der König parierte ihn offenbar durch einen Gegenangriff, wobei er zunächst wohl bis Tēmā vordrang. Auch das Strophengedicht berichtet ja, daß er, ,den Fürsten von Tēmā mit der Waffe tötete" 92 und sich dann seines Landes bemächtigte, seine Untertanen zur Fron zwang. Dies war nur einer der Siege, denn die Stele berichtet genauer davon, daß er sie , in ihrer Gesamtheit" unterwarf, d. h. die zahlreichen Stämme mit ihren jeweiligen Scheichs. Man darf also annehmen, daß der König seine Aktionen weit in die arabische Halbinsel hinein führen mußte, was der Text ja durch die Nennung einzelner Oasen bestätigt. Das benötigte natürlich eine geraume Zeit, und es ist nicht unwahrscheinlich, daß die Angabe von Io Jahren den Tatsachen entspricht, wenn man bedenkt, daß gegen einen Gegner gekämpft wurde, der jederzeit leicht ausweichen und an anderen Stellen wieder erscheinen konnte. Es ist aber eindeutig, daß der König seine Aktivität nach Arabien verlegte, wahrscheinlich, weil es zu einer Expansion nach anderen Seiten keine Möglichkeit mehr gab. Syrien war nach Kämpfen in den ersten Regierungsjahren fest in seiner Hand. Weiter nach Norden vorzudringen, wie es noch Neriglissar vermochte ${ }^{93}$, war durch die Perser verwehrt, mit denen wahrscheinlich ein Abkommen bestand. Auch eine Ausweitung nach Osten verbot sich dadurch von selbst. Einzig der Weg nach Südwesten war noch offen, und hier versuchte der König offenbar, sich eine neue Einflußsphäre zu sichern ${ }^{94}$. Wenig wahrscheinlich erscheint es mir aber, daß der König

$\mathrm{VAB}_{4}, 220,29 \mathrm{zu}$ verstehen. Ähnlich beurteilt Gadd, a. a. O. $76 \mathrm{f}$. die Erwähnung der ,,Mederstadt" in Z. 42 .

92 Kol. II 25. Dieser Passus dürfte also nach der neuen Inschrift - entgegen der von B. Landsberger, ZA 37 (I927) $97^{2}$ geäußerten Ansicht — doch ernst zu nehmen sein.

${ }^{93} \mathrm{CCK} 74-76$. Vgl. S. $37 \mathrm{ff}$.

${ }^{94}$ Schon Nebukadnezar hatte in seinem 6. Regierungsjahr (599 v. Chr.) einen Streifzug gegen Araberstämme unternommen (CCK 7o, 9 f.). Er nahm aber Syrien-Palästina als Ausgangsbasis, d. h. er wandte sich nur gegen die Karawanenstädte am Rande der Wüste. Auch lag ihm wohl nichts an dauerndem Besitz, sondern allein an Raub und Plünderung und einer gewissen Einschüchterung der Beduinen. 
die Araber für eine Allianz gegen Persien gewinnen wollte. Die Stimmung, die das Strophengedicht schildert, herrscht nur in einem eroberten Land, nicht in einem verbündeten ${ }^{95}$. Auch die ,Unterwerfung unter meine Füße" (II 2) bezeichnet einen Akt der Demütigung und Abhängigkeit, der schwerlich dazu angetan sein konnte, treue Bundesgenossen zu gewinnen. Falls die oben (S. 244) erwähnten Nachrichten über eine Eroberung Arabiens durch Kyros noch vor dem Angriff auf Babylonien zutreffen, kann der Versuch Nabonids, in Arabien festen Fuß zu fassen, nur als gescheitert angesehen werden. Falls die These zu Recht bestünde, der König hätte in Arabien Bundesgenossen gegen die Macht im Osten gesucht - etwa auf Grund der Stammesverwandtschaft, wie Landsberger annahm ${ }^{96}$ - , so würde sie doch eine grandiose Fehleinschätzung der Verhältnisse unter den arabischen Stämmen durch Nabonid zur Voraussetzung haben. Wir wissen über die Verhältnisse in Innerarabien aus dieser Zeit noch sehr wenig. Soviel aber darf als sicher angenommen werden, daß es große Reiche und festgefügte Verbände nicht gab, daß vielmehr Beduinen die Situation bestimmten $^{97}$. Nun hat uns das Mâri-Archiv ein lebendiges Bild davon vermittelt, mit welchen Schwierigkeiten selbst ein gut organisierter Staat wie der des Šamši-Adad oder Zimri-Lim zu kämpfen hatte, um die nomadisierenden Stämme am Rande seines Einflußbereiches unter Kontrolle zu bringen oder gar als nützliche Glieder in den Verband des Reiches einzubeziehen. Mit ähnlichen Schwierigkeiten hatten später die Assyrer zu kämpfen, als sie die aramäischen Stämme unter ihre Botmäßigkeit bringen mußten. Es war deshalb von vornherein nicht zu erwarten, daß es Nabonid gelingen könnte, mit arabischen Stämmen eine tragfähige Allianz aufzubauen, und der Zweifel daran, daß er es überhaupt versuchte, ist wohl berechtigt.

95 Strophengedicht II 30-III 6 nach den sehr wahrscheinlichen Ergänzungen Landsbergers. Zum Bau der Residenz , gleich dem Palast von Babylon“ wird die Bevölkerung der Oase in Fron genommen und ihr Vermögen konfisziert. Es ist immerhin möglich, daß der Aufenthalt des babylonischen Hofes in Innerarabien einen gewissen Einfluß auf die kulturelle Entwicklung bis hinunter nach Yemen hatte. Vgl. B. Segall, The Arts and King Nabonidus, A JA 59 (I955) 3I 5-3I 8 zum Fund einer griech. Bronzefigur (Mitte 6. Jh. v. Chr.) in Südarabien, die vielleicht über Tēmā dorthin gelangte. Allerdings fehlen $\mathrm{m}$. W. bisher Bezeugungen von Importstücken dieser Zeit aus Babylonien selbst.

${ }^{96} \mathrm{ZA} 37$ (I927) 95f. Die dort geäußerte Vermutung, die Bewohner Arabiens seien ihrer Sprache nach wahrscheinlich Aramäer gewesen, ist heute etwas zu modifizieren (vgl. z. B. R. Borger, OrNS 26 (I957) 8-II).

$97 \mathrm{Vgl}$. die oben Anm. 73 zitierten Stellen aus dem Kyroszylinder und Berossos, die von ,Zeltbewohnern des Amurru-Landes" sprechen, und s. C. J. Gadd, AnSt. 8, 77 f. 
C. J. Gadd hat jetzt das Zerwürfnis mit der Priesterschaft Babyloniens als eigentlichen Grund für den Aufenthalt in Tēmā herausgestellt ${ }^{98}$, zieht aber auch noch allerlei andere Gründe mit in Erwägung. $\mathrm{Da}$ es nur éin Grund war, der den langen Aufenthalt in Tēmā rechtfertigte, ist ohnehin wenig wahrscheinlich. Eine Vielzahl von Motiven mag zusammengewirkt haben. Ausgehend von einem Feldzuge gegen plündernd ins Land eingefallene Araber bemächtigte sich der König der größten Oasen und brachte damit auch wichtige Handelsstraßen unter seine Kontrolle. Er weitete seine Macht nach Süden aus, da ihm der Osten und Norden versperrt war und versuchte sicher auch, sich dadurch den Rücken zu decken, evtl. schon in Erwartung eines Angriffes der neuen Weltmacht im Osten. Allerdings tat er dies auf herkömmliche Weise durch Unterwerfung, nicht durch Bündnisse. Daneben mag auch die Absicht bestanden haben, die Flammen der Erregung, die seine Bevorzugung des Mondgottes und seines Kultes zu Huarrān in Babylonien entfacht hatte, nicht weiter zu schüren, andererseits aber in einem Lande zu leben, in dem der Kult einer Mondgottheit - z. B. als Reichsgott von Hadramaut - verbreitet war. Da auch die spätere Tradition - neben der Krankheit - religiöse Gründe für den Aufenthalt in der Oase Tēmā verantwortlich macht, dürfte die Absicht des Königs, hier fern aller Streitigkeiten seine Gottheit verehren zu können, keine geringe Rolle gespielt haben. Hauptgrund des Wüstenzuges war sie sicher nicht, das zeigt schon die freudige Reaktion, die der Befehl zur Heimkehr beim König auslöst.

Die Aufgabe des Šamaš, Ergebenheit der Untertanen zu bewirken, setzt voraus, daß zunächst Widerspruch gegen die Politik Nabonids laut wurde. Das entsprach, wie schon mehrfach hervorgehoben wurde, durchaus der Realität. Inwieweit dieses Murren tatsächlich verstummte, läßt sich schwer feststellen. Das Strophengedicht stammt in seiner überlieferten Fassung aus der Zeit des Kyros, es dürfte aber in seiner Substanz auf schon vorher umlaufende Gedichte ähnlicher Art zurückgehen. Ein indirektes Indiz für die immerwährende Opposition stellen die Rechenschaftsberichte in tendenziöser Form dar, wie sie die vorliegenden Stelen, die der Mutter und die Hille-Stele repräsentieren. Auch das Murren der Truppen, von dem das Strophengedicht schreibt (Kol. III $7 \mathrm{f}$.), ist zweifellos oft zu hören gewesen, da die Feldzüge in der Wüste sicherlich gewaltige Opfer forderten. Immerhin ist es trotz der langjährigen Abwesenheit des Königs — offenbar im Mutterlande nicht zu Aufständen gekommen, so daß das Wirken des Sonnengottes dem König darin sichtbar werden konnte.

98 AnSt. 8, 88 f. 


\section{Ankündigung der Rückkehr und Gebet an Sîn}

Die Komposition des Abschnittes II II - III 3 (bzw. 5) ist recht auffällig. Nach Io Jahren ,,waren die Tage erfüllt", was durch ein günstiges Omen des Sîn angedeutet wird. Auf das Stichwort Sîn folgt dann ein langes Gebet an den Gott, das leider am Ende von Kol. II unterbrochen, bzw. abgebrochen ist. Nach dem Zitat aus Ludlul bēl nēmeqi wird dann wiederholt, daß der Zeitpunkt gekommen sei und die Rückkehr auch tatsächlich beschrieben. Im Zentrum des Abschnittes und damit der ganzen Stele steht also das Gebet, das natürlich absichtlich hier eingeschoben wurde, um Sîn für die glückliche Heimkehr zu preisen.

Hier wäre die Frage zu stellen, unter welchem Aspekt Nabonid selbst seinen Wüstenaufenthalt sah. Sie läßt sich nur schwer beantworten, doch scheint es kein günstiger Aspekt gewesen zu sein. Dafür spricht die Bezeichnung als ,Irrweg", falls der Ausdruck richtig gedeutet ist (s. o. S.22gf.). Das geht ferner eindeutig aus der vom König gebrauchten Wendung ikšuda adannu imlû ùmū, ,der Zeitpunkt trat ein, die Tage wurden voll" hervor, die immer dann gebraucht wird, wenn eine Unglückszeit beendet ist und eine glückliche Zukunft erwartet wird ${ }^{99}$. Daran ändert es auch nichts, daß nach dem Verständnis des Königs die Zeit von Sîn festgelegt wurde. Offenbar waren es zwingende Gründe, die ihn in Tēmā festhielten und ihn Io Jahre lang nicht nach Babylon zurückkehren ließen; denn nicht einmal dem Begräbnis seiner Mutter wohnte er bei. Dies ist ein Einwand, den man gegen jeden Erklärungsversuch des Wüstenaufenthaltes machen kann: Kein babylonischer oder assyrischer König hat sich jemals durch irgendein Ereignis jahrelang von seinem Lande fernhalten lassen. Es kann also noch einen Grund gegeben haben, der uns vollkommen verborgen ist - es sei denn, man rechnet wirklich mit einer Krankheit -, der den König an der Rückkehr hinderte. Vielleicht ist aber die negative Beurteilung des Unternehmens, die sich m. E. in den Worten Nabonids spüren läßt, erst rückblickend entstanden, als ihm durch den Abfall der Araber an Kyros die Sinnlosigkeit seiner Eroberung vor Augen trat. Mehr als Vermutungen erlaubt der Text nicht.

Es verwundert nicht, daß der Termin der Rückkehr auf einen nach den Hemerologien günstigen Tag gelegt wurde ${ }^{100}$. Auch in anderen In-

${ }^{99}$ Belege s. oben, S. 23o. Fast regelmäßig ist vom göttlichen Zorn die Rede, der nach 'Erfüllung der Tage' besänftigt ist.

100 Der 17 . Tašrit ist wie in $\mathrm{H}_{2} \mathrm{~A} / \mathrm{B}$ II $\mathrm{I}_{3}$ bestimmt als: 'Sin amēla imangar ",Sîn ist dem Menschen willfährig", s. C. J. Gadd, a. a. O. 67; R. Labat, RA $3^{8}$ (I94I) 33; L. Matouš, Sumer I7 (I96r) 63 III 47, vgl. 38 , I5. 
schriften nimmt Nabonid auf glückverheißende Tage Bezug, einmal auch im Tašrït ${ }^{101}$. Gewöhnlich wird dieser günstige Termin durch ein Orakel bestimmt, doch werden gewisse Ereignisse auch durch Träume angekündigt. Nabonid zeichnet sich ja vor allen anderen Herrschern dadurch aus, daß Träume in seinen Inschriften eine hervorragende Rolle spielen, und auch dic spätere Tradition schreibt dem König ständig Traumgesichte $\mathrm{zu}^{102}$. So ist es zumindest auffällig, daß - von dem Gebet an Sîn durch eine Textlücke getrennt - auch hier von einem Traum die Rede ist (III I-3), und ich möchte das Zitat aus Ludlul I 52. 54 dahingehend verstehen, daß das Ende des Aufenthaltes in Tēmā dem König durch einen Traum mit Erscheinung des Sîn angekündigt wurde.

Das lange Gebet an Sîn, das hier nicht in extenso untersucht werden soll, ist wohl die überschwenglichste Hymne, die Nabonid seinem bevorzugten Gott gewidmet hat und ist sicher typisch für seine religiöse Haltung, die sich hier im fernen Harrān unbeschränkt äußern durfte. Etwas auffällig ist der Anfang mit dem plötzlichen Wechsel in die 2. Person (Z. I5f.), wobei in dem Satz, in den Himmel greifst du ein und die Erde zerbrichst du“ eine Anspielung auf einen bisher unbekannten Neumond-Mythos enthalten sein wird ${ }^{103}$. Der Gedankengang des Folgenden ist klar: Sîn vereinigt alle 'göttlichen Kräfte', die Anus, Enlils und Eas, in sich und ist dadurch , Enlil der Götter“", eine alle anderen Götter überragende Gestalt. Die Ehrfurcht vor ihm erfüllt Himmel und Erde so wie sein strahlender Glanz. Alles ist seiner Willkür ausgeliefert: wo er wohnen will, läßt er sich verehren und schenkt daraufhin Gedeihen, wo er zerstören will, nimmt er die Gottesfurcht hinweg und straft. So wird sein Befehl von allen Göttern und Göttinnen ausgeführt, und selbst die Unterweltsgötter respektieren ihn.

Nach all dem scheint der Vorwurf des Strophengedichts, Nabonid wolle dem ,,Ekur ein Ebenbild an die Seite stellen" (Kol. II 6) durchaus berechtigt zu sein. Das zeigen auch die Epitheta, die Sîn hier und in anderen Inschriften des Königs zugeordnet werden. Er ist vor allem

$101 \mathrm{VAB}_{4}, 220$ I 50; 226 II 60 (Tašrīt); 236 I $54 \mathrm{f}$.

$102 \mathrm{Zu}$ den von A. L. Oppenheim, Dreams S. 202-205 (vgl. S. 250) gesammelten Stellen kommen noch die neuen Belege hinzu: In $\mathrm{H}_{2} \mathrm{~A} / \mathrm{B} \mathrm{I}$ I I- I4 eine verkürzte Form des Traumes im Zusammenhang mit der Errichtung des Ehulhul (VAB $4,2 \mathrm{I} 8 \mathrm{I}$ I6ff.); in $\mathrm{H}_{1} \mathrm{~B}$ II $5 \mathrm{ff}$. eine Erscheinung Sins im Traum der Mutter des Königs. Hier dürfte kaum eine Duplizität der Ereignisse vorauszusetzen sein, vielmehr wird der Hinweis auf den ,, Sendungs-Traum “ in Verbindung mit diesem Tempelbau sich bereits zum literarischen Topos entwickelt haben und entsprechend auch auf die Mutter übertragen worden sein.

${ }_{103}$ Vgl. W. L. Moran, OrNS 28 (1959) 139. 
„König der Götter“"104, sogar „,König der Götter, Herr der Herren“105, ein Titel, der sonst fast ausschließlich Marduk zukommt ${ }^{106}$. ,Enlil der Götter, König der Könige, Herr der Herren"107 werden sonst nur Marduk und Assur genannt, dagegen ist ein Titel wie ,Herr der Götter" 108 nicht auf Marduk festgelegt. Wahrscheinlich täuschen allerdings die Inschriften des Königs, da in denen aus Babylonien konventionell oder aus politischen Rücksichten die Vorrangstellung Marduks nicht bestritten wird, z. B. wird auf ihn fast allgemein die ,Berufung" des Königs zurückgeführt (s. o. Anm. 6I). Marduks Name wird fast ebenso häufig genannt wie der des Mondgottes, wenn auch einmal deutlich mit diesem auf eine Ebene gestellt ${ }^{109}$. Weitaus am häufigsten findet jedoch Šamaš Erwähnung, doch mag hier die Zufälligkeit der Überlieferung eine Rolle spielen, da uns zahlreiche Bauurkunden aus Sippar und Larsa erhalten sind, und der Sonnengott neben Adad auch als Orakelgott fungierte. Neben der Familie des Mondgottes - Ningal, Nusku und Sadarnunna - nehmen dann nur noch die in unserer Inschrift genannten Gottheiten Ištar, Adad und Nergal eine hervorgehobene Stellung ein, denen noch Nabû, der von Nebukadnezar besonders bevorzugte Gott, anzuschließen wäre.

Die Sachlage ist eindeutig, die Suprematur des Mondgottes wird immer wieder hervorgehcben. Es wäre $z u$ fragen, ob sich eine Entwicklung verfolgen läßt, wie es B. Landsberger anzunehmen scheint, wenn er darauf hinweist, in Nbn. Nr. 8 X 30 sei ,,Marduk noch 'Götterherr'"110. Diese Frage hängt eng mit derjenigen nach dem Datum der Restaurierung des Ehulhul zusammen und wird dort (u. S. 257 f.) beantwortet werden können.

104 šar ilāni: $\mathrm{H}_{1}$ B I 7. 12. 39. 44. II 5. IIf. 2I. 23. 28. 34. III $45 ; \mathrm{H}_{2} \mathrm{~A} / \mathrm{B}$ I I 8 . II I2; CT $34,30,38 ; 34,27$; vgl. 27,42 .

šar ilāni ilāni ša ilāni ,, Götterkönig über alle Götter"': VAB 4, 250 ff. I 29. šar ilāni ša šamê u erṣeti, , König der Götter von Himmel und Erde“": $\mathrm{H}_{1}$ B I 33; $\mathrm{VAB}_{4}, 222,26 ; 224,33 ; 252$ II 4 .

105 šar ilāni bèl bètēe: $\mathrm{H}_{2} \mathrm{~A} / \mathrm{B} \mathrm{I} 28$. III 29.

106 So z. B. VAB $4,270 \mathrm{I}_{30}$; $282 \mathrm{IX}_{5} ; 286 \mathrm{X}_{30}$; WVDOG $47, \mathrm{I} 37,24$; K. Tallqvist, StOr. 7 ( 1938$) 233$ f.

${ }_{107} \mathrm{H}_{2}$ A/B II 20. Von Marduk dagegen: UM I 5 , 80 II $_{7} ; \mathrm{CT}_{3} 6,2 \mathrm{I}_{\mathrm{I}}$; $\mathrm{VAB}_{4}$, 218 I $23 ; 260,50$.

108 bèl ilāni: $\mathrm{VAB}_{4}, 252 \mathrm{II}_{3}$; vgl. $\mathrm{H}_{2} \mathrm{~A} / \mathrm{B}$ II I 4 .

bèl îāni ina šamāmu: VAB $4,250,54$.

bèl ilāni (u ištarãte) ša šamê u erșeti: VAB $4,250 \mathrm{I}_{2} 8$; CT $34,37,79 \mathrm{f}$.

bèl ilāni $u$ ištarāte āšibūt šamê (u erșeti): $\mathrm{H}_{2}$ A/B I 5 f.; vgl. CT $34,27,42$ f. $109 \mathrm{VAB} 4,2$ I 8 (Nbn. I) I I8.

110 H. Edhem Memorial I 147 (von mir gesperrt). 


\section{Rückkehr nach Babylon. Bau des Ehulhul}

Die Rückkehr des Königs nach Babylon wird durch eine Huldigung der Fürsten der Umgebung gefeiert, wobei wohl an die staatlichen Würdenträger und die Scheichs der verschiedenen aramäischen Stämme zu denken ist, die auch zum Begräbnis der Mutter des Königs erschienen waren ${ }^{111}$. Vielleicht war in den beschädigten Zeilen auch noch von Sîn die Rede, denn iplahū ilüt-su rabitu , sie fürchteten seine große Gottheit" kann nicht auf den König, sondern nur auf seinen Gott bezogen werden, vgl. $\mathrm{H}_{3}$ I3f. (o. S. 248). Schwer verständlich ist die Bemerkung, daß zu diesem Zeitpunkt auch die Götter zurückkehrten und den König segneten, nachdem sie zunächst erschreckt in der Ferne weilten. Zu erinnern ist an die schwierige Partie des Strophengedichts, die vielleicht von der Auswanderung der Schutzgötter berichtet $^{112}$, und an die entsprechende Stelle, die die Rückführung durch Kyros hervorhebt ${ }^{113}$. Es ist bekannt, daß mehrfach in Kriegszeiten die Gottheiten babylonischer Städte ihre Kultorte verließen und nach Babylon kamen, um dort Schutz zu suchen ${ }^{114}$. Hier muß jedoch gerade der umgekehrte Vorgang angenommen werden, doch wird über den Anlaß zur Flucht nichts gesagt. Man kann vermuten, daß der Einfall der Araber den Anlaß bot, und nun nach Beseitigung dieser Gefahr die Götter wieder ihre Tempel in Ruhe bewohnen können, doch bleibt das ganz unsicher ${ }^{115}$.

Das Thema „Bau des Ehulhul“, das bereits in Kol. I anklang, wird jetzt wieder aufgenommen, wobei der Anschein erweckt wird, als ob nach all den Jahren der König seine Hauptaufgabe nicht vergessen habe, sondern jetzt die Fertigstellung des Heiligtums in Angriff nimmt. Das verleitete Gadd zu dem Schluß, daß die Arbeit am Tempel zwar

$111 \mathrm{H}_{1}$ B II I $8 \mathrm{ff}$., vgl. BHT I I 2, I3- I 5 .

112 I I5- I 8 nach der Úbersetzung von B. Landsberger und Th. Bauer: , [.... du siehst keine Freude, [... hier wohnen] wollen wir nicht mehr!' also beschlossen sie. $[\ldots]$ es verließ seinen Platz der Schutzgott, $[\ldots$. der ....] der Götter weilt in der Fremde." Anders jedoch A. L. Oppenheim, ANET 3rza: , [As to Nabonidus] (his) protective deity became hostile to him, [and he, the former favorite of the g]ods (is now) seized by misfortunes."

113 VI 12 f.: , ,Die Götter von Babylon, männlich und weiblich, bringt er zurück in ihre Zellen, [die Schutzgötter, die ihre Sch]reine verlassen hatten, bringt er zurück in ihre Kulträume." Vgl, auch VAB $3,6,32$.

114 Vgl. z. B. BHT I I3, 9 ff.; CCK 50, 6; 52, I9. 2 I ; 54, 9.

115 Die Nabonid-Kyros-Chronik ist für das I6. Regierungsjahr Nabonids fast vollständig verloren. Vielleicht hat die Erwähnung der Ištar von Uruk (Kol. III 2) und des Meerlandes (ebd. 3) etwas mit der Andeutung unserer Inschrift zu tun. 
bald nach dem Regierungsantritt Nabonids begonnen wurde, daß ihr Abschluß aber erst in die kurze Zeitspanne zwischen der Rückkehr aus Arabien und dem Fall Babylons fiel116. W. L. Moran hält es dagegen mit Recht für wahrscheinlicher, daß der Verfasser der Inschrift die historische Abfolge vernachlässigte, da er gezwungen war, den Bericht über Tēmā und alles Zugehörige in die Bauinschrift Nbn. Nr. I einzufügen $^{117}$. Das läßt sich unschwer dadurch wahrscheinlich machen, daß man die Sätze III I 7 ff. als Fortsetzung von I I3/I4 liest, wodurch der direkte Bezug wiederhergestellt wird, wie er in VAB 4, 2I8/20, I8ff. besteht.

Für die Datierung des Tempelbaus liefert die vorliegende Inschrift keine neuen Kriterien, da sie nur in allgemeinen Worten vom Einsatz aller verfügbaren Kräfte und von reichen Schenkungen an das Heiligtum spricht. Dennoch läßt sich der Zeitraum, in dem die Restaurierung des Tempels erfolgte, mit hinreichender Sicherheit bestimmen. Das politische Manifest Nbn. Nr. 8 (VAB 4, 27off.) enthält in Kol. X I2ff. die Bemerkung, daß das Ehulhul infolge der Zerstörung durch die Ummān-manda 54 Jahre lang in Trümmern lag, jetzt aber aufgebaut werden solle. Der Termin, von dem aus gerechnet wird, ist bekannt: Die Einnahme Huarrāns im Jahre 6ro v. Chr. (s. o. S. 234). 54 Jahre trennen dies Ereignis vom Regierungsantritt Nabonids, wozu stimmt, daß der Traum, der Nabonid den Auftrag Marduks für den Bau des Tempels bringt ${ }^{118}$, ina rēš šarrūtī-ja ,am Anfang meiner Regierung" erscheint. Als weiterer Fixpunkt wird das 3. Jahr des Königs angegeben, in dem Kyros die Meder vernichtend schlug und ihren König Astyages in die Gefangenschaft führte ${ }^{119}$. Dadurch wurde der Weg nach Harrān frei und der Erneuerung des Tempels stand nichts mehr im Wege.

Im Gegensatz dazu steht die Angabe der Nabonid-Kyros-Chronik: Der Sieg über Astyages wird dort zwar ohne genaue Zeitangabe - der Anfang des Abschnittes ist verloren - , aber doch unzweifelhaft unter dem 6. Jahre Nabonids berichtet ${ }^{120}$. Eine der beiden Angaben muß falsch sein, höchstwahrscheinlich die der Chronik. Der Chronist dürfte bei der Abfassung seiner synchronistischen Geschichte die Ereignisse vom 6. Regierungsjahre des Kyros (Eroberung Mediens) versehentlich in die Rubrik vom 6. Jahre Nabonids eingetragen haben, obgleich sie

\footnotetext{
116 AnSt. 8, 72-75.

117 OrNS 28 (1959) I 35 .

$118 \mathrm{VAB}_{4}, 2 \mathrm{I} 8 \mathrm{I}$ I $8 \mathrm{ff}$., s. A. L. Oppenheim, Dreams 203ff.; 250.

$119 \mathrm{VAB}_{4}, 220,28 \mathrm{ff}$; s. B. Landsberger, H. Edhem Memorial I I47.

120 BHT II I (Pl. XII) II I-4. Der folgende Anschnitt, wie jedes Jahr durcb einen Strich abgesetzt, enthält die Ereignisse des 7. Jahres.
} 
in die Rubrik des 3. Jahres gehört hätten. Leider sind wir für die Datierung dieser Ereignisse $\mathrm{m}$. W. noch immer auf die wenigen keilschriftlichen Quellen angewiesen ${ }^{121}$. Aus Herodot, Ktesias, Dinon und Eusebios erfahren wir jedoch, daß die Dauer der Regierung Kyros II. auf 29-30 Jahre festgelegt war, d. h. wohl 29 Jahre und mehrere Monate währte. Der König fand im Sommer 530 an der Ostgrenze seines Reiches den Tod, am I2. August wurde in Borsippa noch eine Urkunde unter seinem 9. Jahre als König von Babylon datiert ${ }^{122}$. Das führt auf das Jahr 560/59 v. Chr. für seinen Regierungsantritt - zunächst als Fürst von Anšan -, und sein 6. Regierungsjahr 554/3 entspricht dem 3. Jahre Nabonids.

Schließlich machen es auch die übrigen Quellen höchst wahrscheinlich, daß der Fehler in der Chronik und nicht bei Nabonid zu suchen ist. Das Strophengedicht berichtet - und wir haben keinen Grund, dieser Angabe zu mißtrauen -, daß Nabonid 2 Jahre nach Vollendung des Baus des Ehulhul seinen Zug nach Tēmā antrat. Wie oben gezeigt wurde, muß der Auszug im 6. Regierungsjahr des Königs erfolgt sein. Die Restaurierung des Tempels gehört also in die Jahre 3-4 Nabonids (553-55I v. Chr.). Schließlich berichtet auch die Mutter des Königs, daß sie die Fertigstellung des Baus noch erlebt habe ${ }^{123}$. Das muß also noch vor ihrem Tod (547 v. Chr.) erfolgt sein und, da auch die Einführung der Götter in das neue Heiligtum durch Nabonid erwähnt ist, noch vor dessen Arabienzug.

Die möglichst exakte Datierung der Restaurierung des Sîn-Heiligtums von Harrān an den Anfang der Regierung Nabonids ist darum von besonderer Wichtigkeit, weil dadurch ein ziemlich untrügliches Indiz dafür gefunden ist, daß sich die Verehrung des Mondgottes beim König nicht allmählich, etwa in bewußtem Gegensatz zur Vorrangstellung des Marduk, entwickelt hat. Vielmehr steht die Suprematur dieses Gottes als „König der Götter" von vornherein fest, auch wenn sich das in den Inschriften zunächst nicht gleichmäßig niederschlägt, sondern im zentralbabylonischen Raum noch Konzessionen an die Tradition gemacht werden. Daß der Kult des Sîn aber von Anfang an dem Programm Nabonids entsprach, bestätigt schließlich noch die Weihung seiner Tochter als En-Priesterin von Ur am 26. September 554, also bereits in seinem 2. vollen Regierungsjahre.

$121 \mathrm{Vgl}$. zum Folgenden den erschöpfenden Artikel von F. Weißbach in Pauly-

Wissowa, Realenzyklopädie der Klassischen Altertumswissenschaft, Suppl. 4

(I924) I129-II66.

122 Parker-Dubberstein, Babylonian Chronology (I956) I4.

${ }^{123} \mathrm{H}_{1}$ B II I $2 \mathrm{ff}$. 
Trotzdem befanden sich auch Bürger von Ur unter denen, die sich "gegen seine große Gottheit verfehlten", es war also nicht der Mondgott dieser Stadt, dem die besondere Fürsorge Nabonids galt. Schon oben (S. 235) wurde darauf hingewiesen, daß der Mondgott von Huarrān unter den letzten Sargoniden eine besondere Rolle spielte. Versuchte Nabonid, hier bewußt eine assyrische Tradition nach 54 Jahren wieder zu beleben? Dafür hat bereits B. Landsberger Argumente beigebracht: Ein Siegel Assurbanipals diente als Vorlage für das neue Kultbild in Harrān; der Tempel wurde auf dem Fundament errichtet, das Assurbanipal legte, dieser als ,Vorgänger“ (rubî älik mahrijja) Nabonids bezeichnet ${ }^{121}$. Diese 'Assyrer-These' verleiht der Reaktion der Babylonier nicht nur religiöse, sondern auch politische Motivation. Nicht allein der verhaßte Kult des Mondgottes von Harrān war es, gegen den sie aufbegehrten, sondern die Gefahr neuerlicher Konsolidierung einer Macht im Norden, von der man sich erst vor wenigen Jahrzehnten freigekämpft hatte. Diese These läßt sich in dieser Form heute nicht mehr aufrecht erhalten, nachdem sich zeigte, daß der Totenkult der Adadguppi nicht assyrischen Herrschern galt und auch keine Datierung nach Assurbanipal erfolgte. Uberhaupt sollte die einzige Stelle, an der Nabonid - historisch richtig - von Assyrern als seinen Vorgängern in Huarrān(!) spricht, nicht überbewertet werden. In anderem $\mathrm{Zu}$ sammenhang werden babylonische Könige wie Nebukadnezar und Burnaburiaš als šar maḩrī bzw. šarru pāna ālik mahrī bezeichnet (VAB 4, 236, 40 ff., in Larsa) oder Kurigalzu und Nebukadnezar als šarru šūt mahrī bzw. šar maȟri (ebd. 246, 32 ff., in Akkade). Asarhaddon erhält dort kein vergleichbares Epitheton. Die Bevorzugung des Gottes von Harrān entsprang offenbar keinen restaurativen Absichten, sondern einem tief verwurzelten persönlichen Glauben des Königs, wobei allerdings die Idee mitgespielt haben kann, durch den Ausbau dieses Kultzentrums die Aramäer Nordsyriens stärker an das Reich zu fesseln und dadurch die Grenze nach Norden, zu dem aufstrebenden persischen Reich, abzuschirmen. Die Reaktion der Babylonier mag dann schlicht als Neid bewertet werden, den der König vermutlich durch größere Bautätigkeit im Kerngebiet des Landes zu beschwichtigen suchte.

Mit der ungewöhnlichen mannu atta-Formel wird schließlich ein Passus eingeleitet, der so stark zerstört ist, daß sich kein zusammenhängender Text mehr herstellen läßt. Aus dem verwandten Text in

$124 \mathrm{VAB}_{4}, 220$ (Nbn. Nr. I) I 48 , s. B. Landsberger, H. Edhem Memorial I $\mathrm{I}_{47} \mathrm{f}$. 
VAB 4, 228 läßt sich aber erschließen, daß hier eine Segensformel gestanden hat, an die sich $u$. U. noch eine Fluchformel anschloß ${ }^{125}$.

Die neuen Texte lösen nicht alle Rätsel, die uns die eigenwillige Gestalt des letzten babylonischen Königs aufgibt. Manche Fragen lassen sich aber heute exakter beantworten und die Deutung einiger Fakten ist $\mathrm{zu}$ modifizieren. Um 6ro geboren, wird Nabonid von seiner Mutter Adad-guppī am babylonischen Hofe eingeführt und vielleicht 585 erstmals mit einer diplomatischen Mission betraut. Über seinen Vater ist nichts Sicheres bekannt. Erst als alter Mann wird er - vielleicht im Sinne einer Übergangslösung streitender Parteien - zum König gemacht. Er war kein Usurpator auf dem Thron, nahm aber das Heft unerwartet tatkräftig in die Hand. Nach Kriegszügen in Kilikien und Syrien kann er um 552 Harrān in Besitz nehmen, nachdem die Meder von Kyros geschlagen sind. Er errichtet dort sofort wieder den Tempel des von ihm besonders verehrten Mondgottes, vielleicht mit der Nebenabsicht, die Aramäer stärker an das Reich zu fesseln und die Grenze im Norden zu sichern. Die protestierenden Babylonier werden von Sîn durch Seuchen und Hungersnot bestraft. Der König begibt sich, wahrscheinlich bei der Verfolgung ins Land eingefallener Araber, nach verschiedenen Oasen der arabischen Halbinsel und betritt sein Land, das unter der Verwaltung des Kronprinzen Bēl-šar-uṣur bleibt, Io Jahre lang nicht. Die Gründe für das lange Fernbleiben lassen sich noch nicht angeben. Es mögen militärische (Guerillakrieg der arabischen Beduinen), politische (Versuch der Unterwerfung und Dienstbarmachung des ganzen Landes) oder religiöse (Verehrung des Mondgottes) gewesen sein. Nabonid scheint rückblickend die Aktion als mißlungen angesehen zu haben. Das mag seinen Grund darin haben, daß Arabien noch vor dem Angriff auf Babylonien in die Hand des Kyros fiel, was auch die Rückkehr des Königs veranlaßt haben wird. Kurz nach der Rückkehr läßt er, um Sîn zu preisen und den Tempelbau gebührend zu würdigen, die vorliegenden Stelen in Harrān aufstellen und rüstet dann das Neujahrsfest des Jahres 539. Am I2. Oktober des gleichen Jahres fällt Babylon den Persern, die wahrscheinlich von der Priesterschaft ins Land gerufen worden waren, kampflos in die Hand, da Nabonid sein Heer offenbar durch lange Wüstenzüge erschöpft hatte. Er selbst wird von Kyros geschont und beschließt sein Leben in Karmanien.

${ }^{125} \mathrm{Vgl}$. W. L. Moran, OrNS 28 (I959) I30f.; I3 I ${ }^{1}$; I34f. 